\title{
Comparative genomics of Lactobacillus crispatus suggests novel mechanisms for the competitive exclusion of Gardnerella vaginalis
}

Teija Ojala ${ }^{1 *+}$, Matti Kankainen ${ }^{1,2 \dagger}$, Joana Castro ${ }^{3}$, Nuno Cerca ${ }^{3}$, Sanna Edelman ${ }^{4}$, Benita Westerlund-Wikström ${ }^{5}$, Lars Paulin ${ }^{1}$, Liisa Holm ${ }^{1,6}$ and Petri Auvinen ${ }^{1}$

\begin{abstract}
Background: Lactobacillus crispatus is a ubiquitous micro-organism encountered in a wide range of host-associated habitats. It can be recovered from the gastrointestinal tract of animals and it is a common constituent of the vaginal microbiota of humans. Moreover, L. crispatus can contribute to the urogenital health of the host through competitive exclusion and the production of antimicrobial agents. In order to investigate the genetic diversity of this important urogenital species, we performed a comparative genomic analysis of L. crispatus.

Results: Utilizing the completed genome sequence of a strain ST1 and the draft genome sequences of nine other L. crispatus isolates, we defined the scale and scope of the pan- and core genomic potential of L. crispatus. Our comparative analysis identified 1,224 and 2,705 ortholog groups present in all or only some of the ten strains, respectively. Based on mathematical modeling, sequencing of additional L. crispatus isolates would result in the identification of new genes and functions, whereas the conserved core of the ten strains was a good representation of the final L. crispatus core genome, estimated to level at about 1,116 ortholog groups. Importantly, the current core was observed to encode bacterial components potentially promoting urogenital health. Using antibody fragments specific for one of the conserved L. crispatus adhesins, we demonstrated that the L. crispatus core proteins have a potential to reduce the ability of Gardnerella vaginalis to adhere to epithelial cells. These findings thereby suggest that L. crispatus core proteins could protect the vagina from $G$. vaginalis and bacterial vaginosis.
\end{abstract}

Conclusions: Our pan-genome analysis provides insights into the intraspecific genome variability and the collective molecular mechanisms of the species L. crispatus. Using this approach, we described the differences and similarities between the genomes and identified features likely to be important for urogenital health. Notably, the conserved genetic backbone of L. crispatus accounted for close to $60 \%$ of the ortholog groups of an average L. crispatus strain and included factors for the competitive exclusion of G. vaginalis, providing an explanation on how this urogenital species could improve vaginal health.

Keywords: Comparative genomics, Lactobacillus crispatus, Pan-genome, Core genome, Normal flora, Bacterial vaginosis, Gardnerella vaginalis, Competitive exclusion

\footnotetext{
* Correspondence: teija.ojala@helsinki.fi

†Equal contributors

'Institute of Biotechnology, University of Helsinki, Viikinkaari 4, PO Box 56, FI-00014 Helsinki, Finland

Full list of author information is available at the end of the article
}

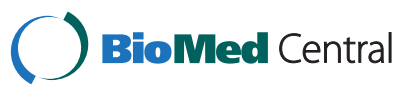

(c) 2014 Ojala et al.; licensee BioMed Central Ltd. This is an Open Access article distributed under the terms of the Creative Commons Attribution License (http://creativecommons.org/licenses/by/4.0), which permits unrestricted use, distribution, and reproduction in any medium, provided the original work is properly credited. The Creative Commons Public Domain Dedication waiver (http://creativecommons.org/publicdomain/zero/1.0/) applies to the data made available in this article, unless otherwise stated. 


\section{Background}

Lactobacilli are an abundant and heterogeneous group of lactic acid bacteria which occupies a wide variety of carbohydrate-rich niches ranging from plant and dairy environments to host-associated habitats. They reside in the oral cavity, gastrointestinal tract (GIT), and genitourinary tract (GUT) of vertebrates. Lately, their occurrence and activity in the human microbiota as well as their potential biotherapeutic effects have gained substantial interest $[1,2]$. The healthy human vagina, for instance, is predominantly colonized by lactobacilli that have a profound impact on the health of women by protecting the host from aberrant urogenital conditions [3-6].

Lactobacillus crispatus is an important urogenital species that is routinely found in the vaginas of healthy women [7-9]. It can account for more than $80 \%$ of all vaginal bacteria [8] and is considered to be one of the most active species in a healthy vagina [10]. L. crispatus also contributes to the maintenance of normal vaginal microbiota, while its absence has been associated with a range of vaginal abnormalities, especially bacterial vaginosis (BV) [10-12]. Strains of L. crispatus are even considered as biotherapeutic agents for reducing recurrent urinary tract infections (RUTI) and BV in women [4-6] and have been shown to inhibit in vitro the growth, viability, and adhesion of uropathogens [13-16], suggesting a role for $L$. crispatus in protecting the vagina from invading pathogens. Specifically, L. crispatus was recently identified to reduce the adhesion of both commensal and pathogenic Gardnerella vaginalis to HeLa cells [17], indicating that competitive exclusion of this BV-associated species could be in key role in the health-promoting effects of $L$. crispatus. Besides the GUT, L. crispatus has been detected in the GIT of animals. The species is among the most profuse lactobacilli in the chicken crop [18] and has, for example, been isolated from the stratified squamous epithelium of the non-secreting portion of the horse stomach [19] and the feces of pigs [20]. L. crispatus has also been recovered from human fecal samples [21,22], but this result is best explained by its presence in oral cavity and rectum [23,24]. Intriguingly, the rectal reservoirs of $L$. crispatus have been associated with a lower prevalence of BV [24,25], suggesting the role of rectal $L$. crispatus in the maintenance of the healthy vaginal flora [25].

Recently, the genome sequences of ten $L$. crispatus strains have become publicly available $[26,27]$. The genomes are all about $2.0-2.7 \mathrm{Mb}$ in size, with a GC content of $\sim 37 \%$. They possess a large number of tRNA molecules (45 to 64) and are predicted to encode 2,022-2,643 proteins, several of which are of potential importance to vaginal health. For example, the potential to inhibit harmful microorganisms by direct inhibition through lactic acid, hydrogen peroxide, and bacteriocins or by displacing them through competitive adhesion is supported by the genome annotation data. In addition, these genomes have verified the phylogenetic position of the species in the Lactobacillus delbrueckii clade $[28,29]$. Out of the ten L. crispatus strains having had their genome defined, nine are vaginal isolates and were sequenced as a part of the Human Microbiome Project [26], including the strain CTV-05 that may have a role in the treatment and prevention of BV and RUTI [4-6]. The remaining genome belongs to the chicken-isolated strain ST1 [27], known for its strong adherence not only to chicken epithelia but also to buccal and vaginal cells of human origin [30-32]. The strain ST1 was recently also characterized to produce a Lactobacillus epithelium adhesin (LEA) that displays specific binding to both crop epithelium and epithelial cells from human vagina [33].

Thus far, the genome sequences of different $L$. crispatus strains have been studied separately. Unfortunately, a single genome sequence may not reflect the entire genomic complement of a species or provide an understanding of the biological processes that are peculiar to the species. Instead, better knowledge of the genetic diversity of a bacterial species can be gained by comparative genomics [34-40]. For example, comparative genomic analyses have established considerable intraspecies genetic diversity within the $L$. delbrueckii clade [34-37], but have also unraveled specific mechanisms of the host-microbe interaction that are common for all strains of the given species [38-40], suggesting speciesspecific rather than strain-specific host interaction properties. In the present study, we used comparative genomics to assess the overall genomic similarity of ten $L$. crispatus strains and defined their core and pan-genome. This global view on the gene content of $L$. crispatus provided an accurate account of features associated with vaginal health and represents the first effort to describe the genomic potential of this central urogenital species. Specific focus was placed on the molecular mechanisms governing host-microbe and microbe-microbe interactions. These mechanisms involve genes encoding or implicated in the production of antimicrobial peptides, adhesion-associated compounds, exopolysaccharide (EPS), and S-layer proteins forming a paracrystalline structure on the cell surface [41-43]. In addition, L. crispatus ortholog data was compared and contrasted with that of G. vaginalis, a frequent and predominant colonizer of the vagina of women with BV $[44,45]$, implicated also in the development of the disease [46]. These analyses revealed collective molecular factors in $L$. crispatus antagonistic to G. vaginalis, such as a counterpart to a G. vaginalis major subunit pilin. The detected factors provided an explanation for the previously reported ability of $L$. crispatus to reduce the adhesion of $G$. vaginalis to host cells [17] and for the inverse association between 
L. crispatus and $G$. vaginalis colonization in the vagina $[12,44,47]$. Overall, this pan-genome study of $L$. crispatus broadens our knowledge of this central vaginal colonist and sheds light on the molecular mechanisms by which $L$. crispatus could prevent BV and protect the vagina from pathogens.

\section{Materials and methods}

\section{Genome entries and strains}

All available genome sequences of $L$. crispatus in public databases as of January 2013 were included in this work (Table 1). In addition, all available genome sequences of G. vaginalis with annotated coding sequences (CDSs) in their genome files as of May 2014 were included in the G. vaginalis genome analyses (Additional file 1). To resolve the phylogenetic position of $L$. crispatus in respective to closely related lactobacilli, genomes of Lactobacillus helveticus, Lactobacillus acidophilus and Bacillus subtilis were downloaded and analyzed together with the L. crispatus genomes. The set of L. helveticus, L. acidophilus and B. subtilis genomes included in this phylogenetic analysis is listed in Additional file 2. The annotated genomes were retrieved in GenBank format from GenBank [48] or PATRIC [49]. For the draft genomes, supercontigs were preferred, if available.

For adhesion assays, G. vaginalis strain 101 isolated from a woman with BV [50] and a vaginal Lactobacillus crispatus strain EX533959VC06 isolated in the scope of the project "The Vaginal Microbiome: Disease, Genetics and the Environment" of the Human Microbiome Project [26] were used.

\section{Reference-based genome scaffolding}

The draft genomes of L. crispatus (strains 125-2-CHN, 214-1, CTV-05, FB049-03, FB077-07, JV-V01, MV-1AUS, MV-3A-US, and SJ-3C-US), L. helveticus (strains DSM 20075 and MTCC 5463), and L. acidophilus (strain ATCC 4796) were subjected to reference-based genome scaffolding using progressive Mauve genome alignment software with default settings [51]. The genome sequences of the strains ST1, DPC 4571, and NCFM served as references for the L. crispatus, L. helveticus, and L. acidophilus draft genomes, respectively. The contig order was confirmed through whole genome sequence comparisons that were generated using BLASTN [52], and visualized using the Artemis Comparison Tool (ACT) [53]. Putative plasmid-derived contigs among $L$. crispatus genomes were separated from chromosome derived sequence fragments using cBar with default settings [54]. Potential plasmidderived contigs $2.5 \mathrm{~kb}$ or longer were then extracted and aligned to known plasmid sequences using PATRIC's BLASTN [49]. Contigs that aligned at $\geq 40 \%$ identity over $\geq 70 \%$ of their length were considered as plasmid-derived.

\section{Phylogenetic analyses}

The organized scaffolds of the 18 strains of L. crispatus, L. helveticus, and L. acidophilus were aligned using Mauve Progressive Aligner [51]. Fully conserved columns with single nucleotide polymorphism (SNP) were extracted with Mauve genome alignment software [51], and used for the construction of the phylogenetic tree using PhyML with default settings [55]. Maximum-likelihood trees were visualized with iTOL [56]. For correct rooting of the phylogenetic tree, a SNP-based phylogenetic tree including the $B$. subtilis genome as an out-group was constructed using the same approach.

\section{Genome re-annotation}

In order to ensure the identical quality standards for all the investigated genomes, a functional annotation update was performed for L. crispatus CDSs. Additional annotation information for the CDSs was obtained with Blannotator [57], best BLAST, Rast [58], the automatic annotation server (KAAS) [59], COG functional classification system [60], and by searching the predicted protein products against the PFAM database release 26.0 [61]. For Blannotator and best BLAST approach, BLASTP was run with default parameter settings, and hits that aligned with more than $40 \%$ amino-acid identity and $80 \%$ coverage threshold were retained. The Rast [56] and KAAS [57] and COG [58] annotation was obtained using the services with default settings. PFAM searches were performed locally using the HMMer 3.0 package [62], relying on the PFAM trusted cut-off for the score. The EPS gene clusters were identified by manual examination of the annotation information. The presence of putative bacteriocin-encoding genes was determined with BAGEL3 [63] with default settings. To identify genes associated with clustered regularly interspaced short palindromic repeats (CRISPRs), CDSs were screened for the presence of CRISPR-associated (Cas) protein domains using the hmmscan program from the HMMer 3.0 package [62]. Matches having scores exceeding the trusted cut-off values were considered significant. Cas protein domain models were obtained from the TIGRFAM database $[64,65]$. Integration of annotation information was done using in-house perl scripts producing tab-delimited CDSs information files.

Other bioinformatic analyses included identification of mobile genetic elements and CRISPR loci. Genomic regions potentially obtained by horizontal gene transfer (HGT) were predicted using IslandPick, IslandPathDIMOB and SIGI-HMM methods with the help of IslandViewer meta-analysis tool with default settings [66]. Prophage-like gene-clusters were predicted with Prohinder using default parameters [67]. Overlapping prophage-like genome regions were merged into single extended regions spanning a given genomic region and 
Table 1 Overview of $L$. crispatus strains, properties and main findings

\begin{tabular}{|c|c|c|c|c|c|c|c|c|c|c|c|c|}
\hline Strain \& accession & Scaffolds & $\begin{array}{l}\text { Plasmid derived } \\
\text { contigs }\end{array}$ & $\begin{array}{l}\text { Genome } \\
\text { size }(\mathrm{Mb})\end{array}$ & $\begin{array}{l}\text { Conserved } \\
\text { genome (\%) }\end{array}$ & CDS & $\begin{array}{l}\text { Ortholog } \\
\text { groups }\end{array}$ & $\begin{array}{l}\text { Average CDS } \\
\text { length }\end{array}$ & $\begin{array}{l}\text { CRISPR/Cas } \\
\text { system }\end{array}$ & $\begin{array}{l}\text { Prophage } \\
\text { clusters }\end{array}$ & Gls & Adhesins & Comments \\
\hline $\begin{array}{l}\text { 125-2-CHN } \\
\text { [GenBank:ACPV00000000] }\end{array}$ & 30 & 0 & 2.31 & 86 & 2082 & 2050 & 902 & Type ॥ & 1 & 6 & 9 & $\begin{array}{c}\text { Vaginal isolate from a healthy } \\
\text { Chinese woman }\end{array}$ \\
\hline $\begin{array}{l}\text { 214-1 } \\
\text { [GenBank:ADGR00000000] }\end{array}$ & 187 & 1 & 2.07 & 97 & 2163 & 2135 & 847 & Type II & 2 & 7 & 10 & Human vaginal isolate \\
\hline $\begin{array}{l}\text { CTV-05 } \\
\text { [GenBank:ADML00000000] }\end{array}$ & 25 & 0 & 2.36 & 90 & 2248 & 2032 & 838 & Type ॥ & 6 & 8 & 9 & $\begin{array}{l}\text { Human vaginal isolate; strong } \\
\text { adhesion to vaginal cells; health } \\
\text { promoting use in treatment and } \\
\text { prevention of BV and RUTI }\end{array}$ \\
\hline $\begin{array}{l}\text { FB049-03 } \\
\text { [GenBank:AGZF00000000] }\end{array}$ & 5 & 0 & 2.46 & 92 & 2433 & 2332 & 848 & Type II & 3 & 8 & 11 & Human vaginal isolate \\
\hline $\begin{array}{l}\text { FB077-07 } \\
\text { [GenBank:AGZG00000000] }\end{array}$ & 10 & 1 & 2.70 & 84 & 2643 & 2516 & 837 & Type II & 3 & 21 & 13 & Human vaginal isolate \\
\hline $\begin{array}{l}\text { JV-V01 } \\
\text { [GenBank:ACKR00000000] }\end{array}$ & 86 & 0 & 2.22 & 90 & 2209 & 2180 & 839 & Type II & 2 & 5 & 12 & Human vaginal isolate \\
\hline $\begin{array}{l}\text { MV-1A-US } \\
\text { [GenBank:ACOG0000000] }\end{array}$ & 45 & 0 & 2.31 & 90 & 2151 & 2126 & 877 & Type II & 6 & 8 & 9 & $\begin{array}{c}\text { Vaginal isolate from a healthy } \\
\text { US woman }\end{array}$ \\
\hline $\begin{array}{l}\text { MV-3A-US } \\
\text { [GenBank:ACQC00000000] }\end{array}$ & 76 & 0 & 2.44 & 89 & 2330 & 2275 & 859 & Type II & 6 & 14 & 9 & $\begin{array}{c}\text { Vaginal isolate from a healthy } \\
\text { US woman }\end{array}$ \\
\hline $\begin{array}{l}\text { SJ-3C-US* } \\
\text { [PATRIC:ADDT00000000] }\end{array}$ & 201 & 1 & 2.09 & 97 & 2174 & 2138 & 821 & Type II & 1 & 15 & 10 & $\begin{array}{c}\text { Vaginal isolate from a healthy } \\
\text { US woman }\end{array}$ \\
\hline $\begin{array}{l}\text { ST1 } \\
\text { [GenBank:NC_014106] }\end{array}$ & 1 & 0 & 2.04 & 82 & 2022 & 1957 & 896 & Type I & 0 & 10 & 11 & $\begin{array}{c}\text { Chicken isolate; adheres also to } \\
\text { human vaginal cells; inhibition } \\
\text { of APEC adhesion }\end{array}$ \\
\hline
\end{tabular}

*Annotations are derived from PATRIC.

BV: Bacterial vaginosis; RUTI: Recurrent urinary tract infection; APEC: Avian pathogenic Escherichia coli. 
manually inspected. Putative CRISPR loci were identified with PilerCR run with default settings [68] and manually adjusted. MegaBLAST (default parameters) [52] was used for similarity searches between CRISPR-spacer sequences and virus (taxid:10239) and plasmid (taxid:36549) entries in the GenBank database. Only matches showing 100\% identity over the complete CRISPR-spacer were retained.

\section{Annotation of proteinaceous adhesion factors}

L. crispatus CDSs potentially involved in binding to the host were identified by searching the predicted protein sequences against adhesion associated PFAMs. Adhesion associated PFAMs were identified by searching the PFAM database release 26.0 [61] entries with various keywords related to adhesion, host tissue components, and bacterial surface components, and by manual examination of the literature. The list of PFAM domains is available in Additional file 3 . In addition, non-adhesion related domains for the selected adhesion-related CDSs were detected by searching the protein sequences against PFAM release 27.0 through the PFAM website using gathering thresholds greater than or equal to the trusted cut-off.

\section{Ortholog prediction}

Ortholog groups among L. crispatus strains were identified using OrthoMCL [69]. To estimate the development of the size of the core and pan-genome as a function of the number of sequenced L. crispatus strains, ortholog groups were determined iteratively for an increasing numbers of sequenced genomes. At each sample size, the analysis was repeated 50 times with different random sets of L. crispatus genomes. OrthoMCL was run with default settings, except for a percent match threshold of 35 and BLASTP set to print up to 10,000 alignments. The protein products of the original CDSs were used for the analysis. The same approach, but without the sampling procedure, was used to define the ortholog groups among $G$. vaginalis. Because of the draft quality of most of the G. vaginalis genomes, ortholog groups present in $\geq 30 \mathrm{G}$. vaginalis genomes were considered as core groups.

\section{Estimation of $L$. crispatus pan- and core genome sizes}

The estimation of the L. crispatus core and pan-genome sizes was based on the OrthoMCL results and was performed according to previously described approaches [70]. The core genome was extrapolated by fitting an exponential decaying function $y=\kappa \exp (-N / \tau)+\Omega$ to the median number of core ortholog groups with a weighted least square regression. In the equation, $N$ is the number of sequenced strains and $\kappa, \tau$, and $\Omega$ are free parameters optimized in the regression analysis. The $\Omega$ describes the estimated core genome size. The power law $y=k N^{\beta}$ was fitted to pan-genome data with a weighted least square regression, where $y$ is the median, $N$ is the number of genomes, and $k$ and $\beta$ are free parameters. Regression analyses were done using the $n l s$ function of the statistical software R [71].

\section{Identification of significant enrichment of genes in COG-categories}

Hypergeometric distribution was used to test the probability of the over-representation of core, strain-specific or variably conserved accessory genes in a given cluster of orthologous groups (COG). The obtained $p$-values were subjected to Bonferroni adjustment to reduce the number of false positives introduced by multiple hypothesis testing. Only COG categories containing more than $20 \mathrm{CDSs}$ were included in the analysis. Statistical tests were performed using the statistical software R [71].

\section{Identification of antagonistic factors against $G$. vaginalis}

Virulence-related G. vaginalis CDSs were inferred from a recent comparative genomic analysis [72] and by comparison to the PFAM database [61]. The PFAM search was done using the hmmersearch program from the HMMer 3.0 package. Hits were considered significant if their score was above a trusted cut-off value. Virulencerelated PFAM models were identified based on a literature review. Following the identification of G. vaginalis virulence factors, all the members of their ortholog groups were extracted, an alignment built using Muscle with default settings [73], and a hidden Markov model (HMM) constructed using the hmmbuild command. The constructed HMMs were then searched against the predicted L. crispatus proteomes with the hmmersearch program from the HMMer 3.0 package in order to identify counterparts. Hits with E-value greater than or equal to 0.01 were accepted and manually inspected.

\section{Detection of enzymes and metabolic pathway reconstructions}

Using the automatic annotation server KAAS [59], L. crispatus CDSs were assigned with EC numbers describing enzymatic activity. Each strain's ability to ferment carbohydrates and synthetize bio-compounds was then tested by matching its EC complement against the sets of ECs of metabolic reactions providing the conversion of a given starting compound to a particular end product. A route was accepted as intact if at least one match was found for each enzyme-catalyzed reaction. Metabolic routes between two given compounds were retrieved from the FMM server [74] which connects different KEGG reference reaction maps [75] and reconstructs metabolic pathways between metabolites. For the analysis, the amino acids were paired with amino acid synthesis starting materials and with each other; carbohydrates were paired with selected key 
intermediates of the central carbon metabolism; the selected central carbon metabolism intermediates were paired with pyruvate or pyruvate, acetate and ethanol; and pyruvate was paired with various end products. The exact list of compound pairs screened is available in Additional file 4 . To determine pathways encoded by the $L$. crispatus core genome, the above pathway reconstruction approach was repeated for the core genome-encoded EC complement. Finally, the mode of carbohydrate fermentation was studied based on MetaCyc pathways for homolactic and heterolactic fermentation [76]. Hydrogen peroxide generating enzymes were detected by screening for EC numbers of the enzymes having the compound $\mathrm{H}_{2} \mathrm{O}_{2}$ (C00027) as a product.

\section{Adhesion assays}

Bacteria were grown in supplemented brain heart infusion (Oxoid) containing 2\% (w/w) gelatin (Oxoid), 0.5\% yeast extract (Liofilchem), $0.1 \%$ starch (Fisher Scientific) and $0.1 \%$ glucose (Liofilchem), for $48 \mathrm{~h}$ at $37^{\circ} \mathrm{C}$, in $10 \%$ $\mathrm{CO}_{2}$. Bacterial suspensions were collected by centrifugation at $6,960 \mathrm{~g}$ at $4^{\circ} \mathrm{C}$ for $10 \mathrm{~min}$ and washed once with sterile phosphate buffered saline (PBS). Bacteria were resuspended in PBS and the optical density at $600 \mathrm{~nm}$ (OD600) was determined. Correlations between OD600 and Colony Forming Units (CFUs) were made prior to the experiments, and the bacterial suspensions were adjusted to $1 \times 10^{8} \mathrm{CFUs} / \mathrm{mL}$, as optimized before [17].

For the adhesion assays, HeLa cells (American Tissue Culture Collection, ATCC CCL-2) were cultured in DMEM supplemented with $10 \%$ (vol/vol) fetal bovine serum (Sigma-Aldrich) and $1 \mathrm{IU}$ penicillin-streptomycin $/ \mathrm{mL}$ (Sigma-Aldrich) at $37^{\circ} \mathrm{C}$ and in $5 \% \mathrm{CO}_{2}$. Cells were cultured in chamber slides (Lab-Tek) until they reached a density of $2 \times 10^{5}$ cells per well ( $\approx 90 \%$ confluence), at $37^{\circ} \mathrm{C}$ in $5 \% \mathrm{CO}_{2}$. Before the adhesion assays, cells were washed twice with $200 \mu \mathrm{L}$ of PBS to remove nonadherent cells and fixed with cold $4 \%$ (w/v) paraformaldehyde (PFA; Santa Cruz Biotechnology, Inc.) in PBS for $10 \mathrm{~min}$ followed by washing three times with PBS.

Fab fragments prepared by papain treatment of purified IgG against LEA protein of L. crispatus ST1 and flagellum of Escherichia coli strain MG1655 $\Delta$ fimA-H were available from a previous study [33]. Fab fragments (final concentration $0.7 \mathrm{mg} / \mathrm{mL}$ ) in PBS supplemented with $5 \mathrm{mM}$ phenylmethylsulfonyl fluoride (PMSF; Sigma-Aldrich) were mixed in independent experiments with $G$. vaginalis or L. crispatus cells, at room temperature, for $30 \mathrm{~min}$, with rotational agitation at $0.028 \mathrm{~g}$. Mixtures of Fab fragments and bacteria or bacteria alone in PBS supplemented with 5 mM PMSF were incubated with PFA-fixed HeLa cells for 1 hour, at $37^{\circ} \mathrm{C}$ in $5 \% \mathrm{CO}_{2}$. Each well was carefully washed twice with $200 \mu \mathrm{L}$ of sterile PBS to remove nonadherent bacteria. Bacterial quantification was done as previously described [77]. Briefly, after fixing with methanol, DAPI $(2.5 \mu \mathrm{g} / \mathrm{mL}$; Sigma-Aldrich) was added to the wells. Microscopic visualization was performed using an Olympus BX51 epifluorescence microscope equipped with a CCD camera (DP72; Olympus) and filters capable of detecting the DAPI staining (BP 365-370, FT 400, LP 421). The number of adherent bacteria in 20 randomly chosen microscope fields was determined using Image $J$ software (version 1.41). Results were expressed as the bacteria per HeLa cells, according the mean \pm standard deviation of the two independent experiments, with technical duplicates. The data were analyzed using the Student's $t$-test with the statistical software package SPSS 17.0 (SPSS Inc. Chicago, IL). P-values of less than 0.05 were considered significant.

\section{Results and discussion}

\section{General genomic features of $L$. crispatus}

The genome sequences of ten $L$. crispatus strains were compared and analyzed (Table 1). These genomes contain 22,455 CDSs, of which 13,774 (61.3\%) had an assigned role in the original genome file. After the annotation update, 19,414 CDSs (86.5\%) were functionally classified by at least one of the functional annotation tools. For each CDS, the results of the different protein classification analyses were collected together and analyzed as a group. The obtained annotations are presented in Additional file 5. Only one of the genomes (ST1) is in one contig whereas the rest are in 5-201 super-contigs. Putative plasmid-derived sequences, each with a length of 2,000 bases or more were identified in three vaginal isolates (214-1, FB077-07 and SJ-3C-US), the rest having only chromosomal-associated super-contigs. Using conserved genomic synteny, the orientation and order of the chromosomal-associated super-contigs of each draft genome was determined. Analyses of the resulting architecture revealed that genomes were in general collinear (Figure 1) and shared on average $~ 90 \%$ of each other's content, comparable to conservation ratios seen in Lactobacillus johnsonii [35], L. helveticus [34], and L. plantarum [78]. The genomes of the strains 214-1 and SJ-3C-US were most conserved, with $\sim 97 \%$ of their sequences conserved in at least one strain, whereas only roughly $82 \%$ and $84 \%$ of the genomes of strains ST1 and FB077-07 could be aligned against some other L. crispatus genome (Table 1 ). These data indicate that each assembly presents a near complete chromosome, providing a solid foundation for inter-strain comparisons.

\section{The $L$. crispatus pan-genome}

The microbial pan-genome is defined as the full complement of genes in a species [79]. In total, this set of L. crispatus genomes comprised 3,929 ortholog groups, including on average 5.2 orthologs and 0.2 co-orthologs 


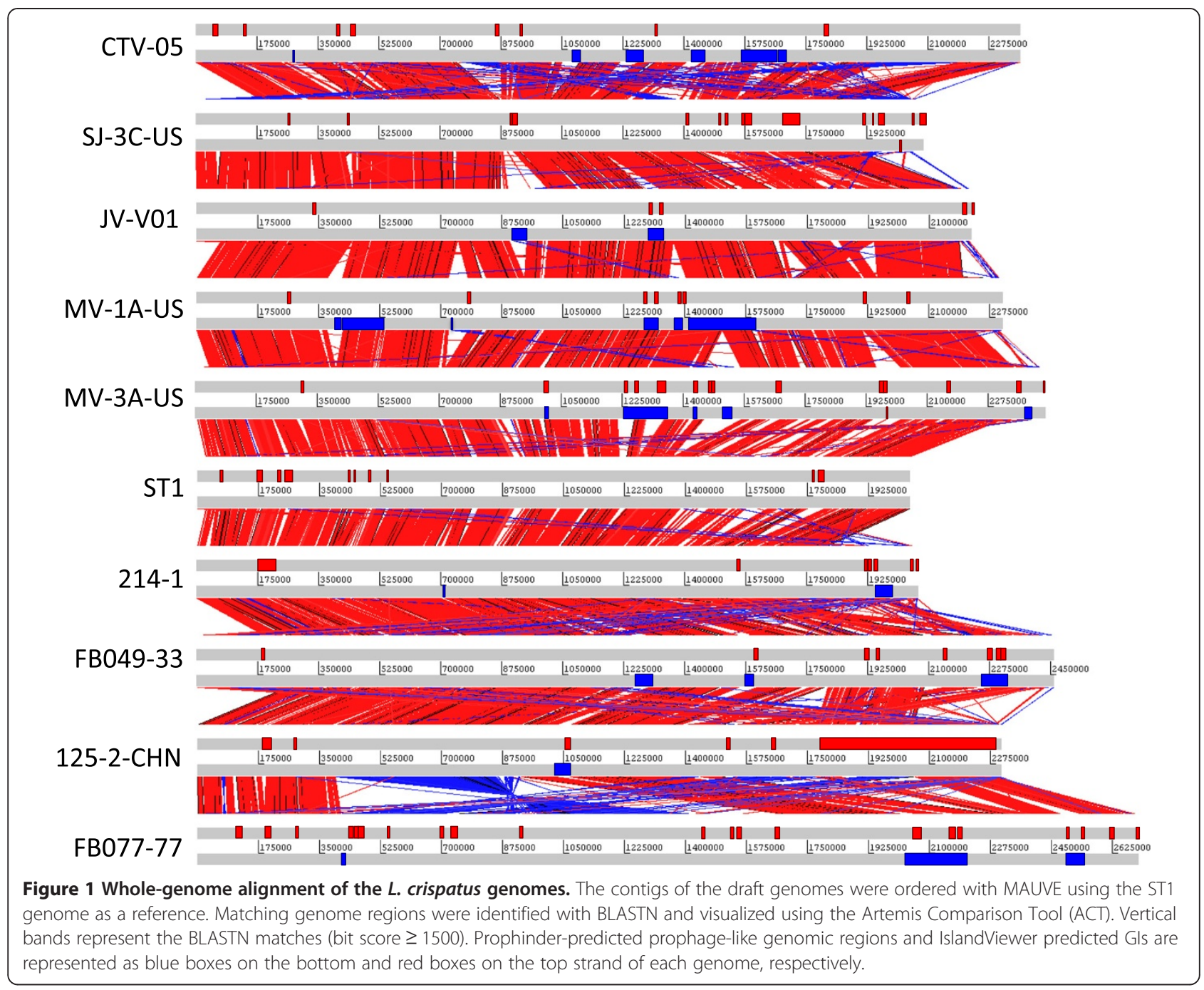

per group. This current pan-genome was defined using OrthoMCL and was almost twice the average number of CDSs $(\sim 2,250)$ and ortholog groups $(\sim 2,170)$ present in a single L. crispatus strain (Table 1). The ortholog group accumulation curve describing the expansion of the pangenome as a function of genomes added to the analysis fitted well a power law model and was far from saturated (Figure 2A), indicating that the total gene pool accessible to the species has not yet been fully captured [79] and suggesting yet-to-be discovered traits in L. crispatus, similar to that what has previously been reported for Oenococcus oeni [80] or Lactobacillus paracasei [38]. Particularly, the regression model [70] revealed an open pan-genome (positive exponent $\beta=0.282 \pm 0.006$ ) that grows by at least ten ortholog groups per every additional genome until 285 isolates have had their genome defined.

\section{The $L$. crispatus core genome}

The core genome is defined as the orthologous genes present in every strain of a species [79]. We identified the current $L$. crispatus core genome to be comprised of 1,224 ortholog groups that were conserved across all the ten analyzed strains. This common core captured $\sim 57 \%$ of the ortholog groups of a given genome, which is slightly less than what orthologous grouping has revealed for another Lactobacillus species [38]. Based on the examination of the COG functional categories and hypergeometric tests $(p$-value $\leq 0.01)$, the core was identified to be significantly enriched with genes belonging to COG categories J (translation), $\mathrm{T}$ (signal transduction), and $\mathrm{E}$ (amino acid metabolism and transport) (Figure 2C). Furthermore, $\sim 10 \%$ of the ortholog groups in the core genome could not be assigned with a descriptive functional annotation (Additional file 5), and thus may represent proteins with yet-to-be discovered housekeeping functions or other functions relevant to the basic aspects of the biology of the species. We also predicted the core genome to contain genes encoding features likely to contribute to cell envelope biogenesis, antimicrobial activity, and hostmicrobe interaction, as illustrated in detail below. 


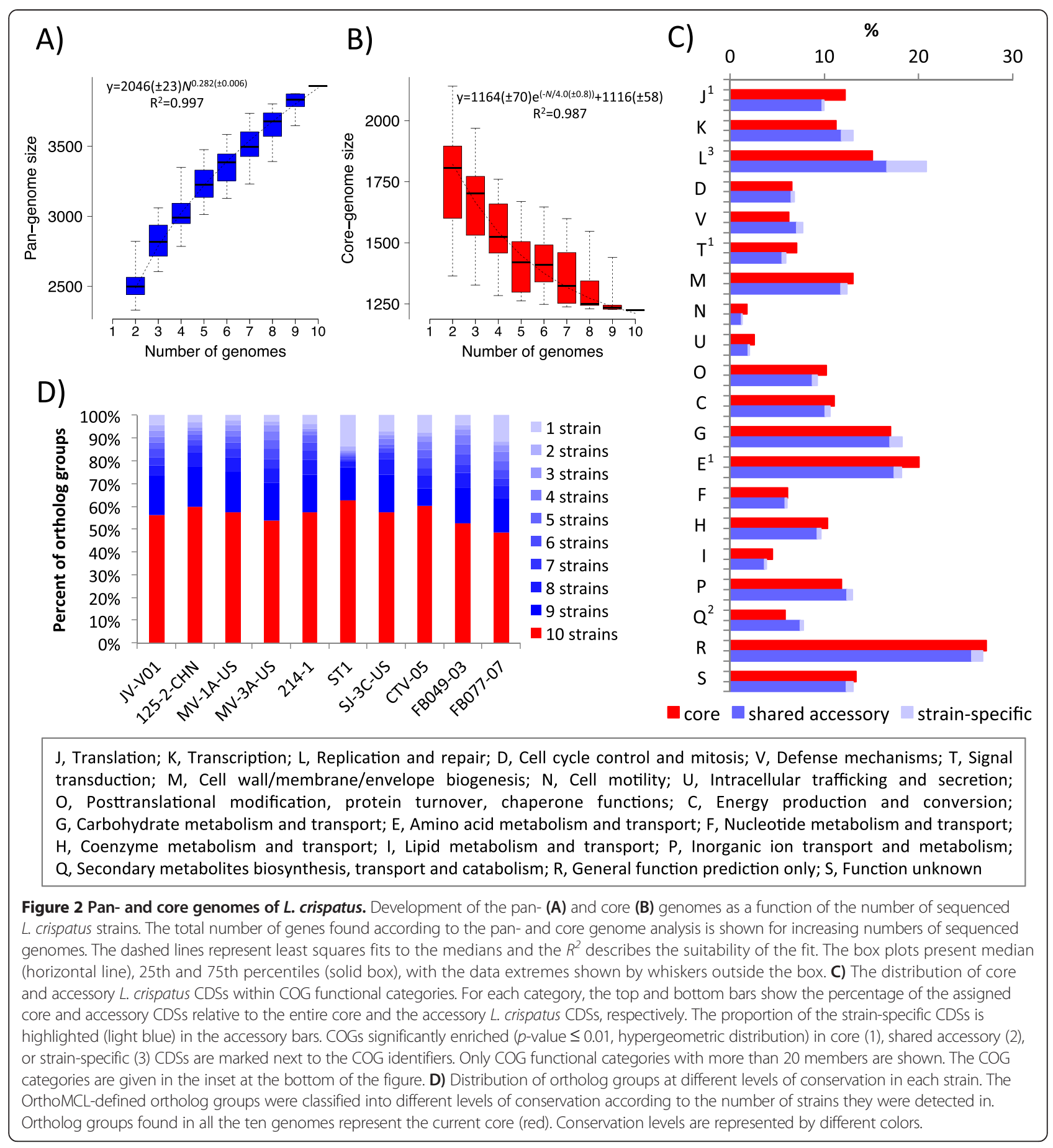

To estimate the number of ortholog groups present in an infinite number of $L$. crispatus strains, the number of shared ortholog groups found on sequential addition of each new genome sequence was extrapolated by fitting an exponential decaying function to the medians of core genome sizes [70]. As expected, the number of ortholog groups in the core genome initially decreased with the addition of each new genome sequence. The extrapolation of the curve designated that the core genome plateaus at $1116 \pm 58$ ortholog groups for an infinite number of $L$. crispatus strains (Figure 2B). Thus, the current L. crispatus core genome appears to be almost within the estimated error margin, indicating that the current core is nearly a perfect representation of the final core genome. However, it should be noted that gaps and sequencing errors in draft assemblies might have affected our estimate [81]. 


\section{The $L$. crispatus variome}

We investigated the distribution of the L. crispatus pangenome by assessing the number of strains sharing a particular ortholog group (Figure 2D). In total, 2,705 ortholog groups were present in some, but not in all the ten $L$. crispatus strains, forming the current L. crispatus accessory genome, suggested to provide selective advantages for different strain(s) of a species [70,79]. The overall composition of the COGs in the core and accessory genomes was mainly similar (Figure $2 \mathrm{C}$ ), the most notable $(p$-value $\leq 0.01)$ over-representations of accessory genome-encoded genes being associated with COG categories L (replication and repair) and Q (secondary metabolites biosynthesis, transport and catabolism). Enrichment in the $\mathrm{L}$ and $\mathrm{Q}$ categories was driven by diversity in strain-specific transposon-associated classes and ABC-type multidrug transporters, respectively. Included in the accessory genome were also 1,311 ortholog groups found only in a single strain. Most of these ortholog groups belonged to the genomes of the strains FB077-77 and ST1 (287 and 264, respectively), which also displayed the smallest $(733)$ and largest $(1,292)$ accessory gene pools, respectively. Fewest strain-specific groups were present in the genome of the strain MV-1AUS. The mean number of the strain-specific ortholog groups found in the L. crispatus dataset was $131 \pm 84$, which forms a slightly bigger portion of the genome than what comparative analyses have previously detected in another Lactobacillus species [82] and less than in some other lactic acid bacteria such as O. oeni [80]. As expected, the strain-specific gene pool is poorly characterized, close to $40 \%$ lacking a functional annotation. Interestingly, transposase-related genes accounted for $\sim 25 \%$ of all strain-specific genes with an informative functional annotation. Protein homology searches revealed that $~ 30 \%$ of all strain-specific genes had the highest similarity to genes found in other strains of the L. delbrueckii clade (Additional file 6). The species L. helveticus and Lactobacillus kefiranofaciens were deduced to be the two most notable reservoirs of genetic variability, providing the best matching targets for about $10 \%$ and $5 \%$ (respectively) of the strain-specific ortholog groups in L. crispatus. For example, up to $47 \%$ of strain-specific ortholog groups in strain SJ-3C-US had the top match in L. helveticus. In addition, more distant Lactobacillus species appear to have interacted with L. crispatus. Specifically, the strain ST1 seems to have received seven strain-specific ortholog groups from Lactobacillus salivarius, which is only distantly related to L. crispatus ST1 but known to exist in the same ecological niche [18].

\section{Horizontal gene transfer}

HGT is a major force in bacterial evolution and can contribute to the fitness, metabolic versatility, and niche-adaptation of bacteria [83]. For example, genomic islands (GI) harboring genes for carbohydrate utilization reflect to the lifestyle adaptation of Lactobacillus plantarum [78]. To determine the presence of GIs and potentially horizontally acquired genes, the L. crispatus genomes were interrogated using IslandViewer [66]. This analysis identified between 5 and 21 GIs in each genome (Table 1). Some of these GIs agreed with the observed interruptions in the genomic synteny whereas others were conserved (Figure 1), highlighting the imprecision of the prediction methods or indicating the presence of ancient GI acquisition events in L. crispatus. The total span of GIs was longest in L. crispatus 125-2-CHN ( 574 kb), shortest in the strain JV-V01 $(\sim 47 \mathrm{~kb})$, and on average $\sim 166 \mathrm{~kb}$ in a L. crispatus genome. Based on COG and prophagecluster analysis, over 500 of the total of 1,571 CDSs in the GIs encoded phage-related products or transposases, which is not surprising, given that many of the prophagelike genomic regions co-localize with the GIs (Figure 1). In addition to the mobile elements, the GIs were found to be rich in metabolism and biosynthesis-related genes. Close to $20 \%$ of their gene content was predicted to be involved in sugar metabolism and amino acid biosynthesis, pointing a role for HGT in adaptation of L. crispatus to varying environments. For example, HGT events may have contributed to acquisition of cellobiose and fructosespecific transport systems as well as genes implicated in sialic acid utilization to certain L. crispatus strains (Additional file 5). On the other hand, the more ancient gene acquisition events in $L$. crispatus provide an explanation for the observed presence of an additional copy of phosphoketolase genes missing in the closely related $L$. acidophilus and $L$. helveticus genomes included in the phylogenetic analysis. Similarly, the investigated L. acidophilus and L. helveticus strains also lacked a GI-associated mannosylglycerate hydrolase encoding genes present in some L. crispatus strains. Moreover, missing from L. acidophilus genomes were also a hydrogen peroxide producing glycolate oxidase (EC:1.1.3.15) gene that was present in all the L. crispatus and most L. helveticus genomes, further supporting the role of HGT in environmental adaptation. Another hydrogen peroxide producing enzyme, puryvate oxidase, was in contrast predicted to be present in all except three L. crispatus, L. helveticus, and L. acidophilus genomes. The L. crispatus GIs comprised also several putative EPS biosynthesis genes in strains ST1, 125-2-CHN, and FB049-03, which is in accordance with the observation that EPS gene clusters in lactobacilli often have abnormal GC content [84]. Finally, 145 strain-specific genes were associated with GIs. Most of these were distributed somewhat randomly, but it was also possible to define eight long (minimum of five genes) GIs with considerably many strain-specific genes and probably thus acquired rather 
recently by HGT. In three of these GIs (EKB62214.1EKB62134.1, EKB62035.1-EKB62043.1 and LCRIS_017 45-LCRIS_01757), the majority of the CDSs did not show significant similarities to proteins in the NCBI databases, suggesting a recent acquisition of yet-undiscovered traits.

\section{Phages}

Temperate phages are common in vaginal lactobacilli and can form a potential threat for Lactobacillus populations maintaining a healthy vagina [85-87]. Some studies have even suggested that bacteriophage attack is the causative agent triggering the breakdown of the protective vaginal microbiota during BV $[86,87]$. In this study, a total of 31 prophage-like regions were identified comprising of 1,636 CDSs and accounting for more than a fifth of the ortholog groups in L. crispatus. Markedly, this fraction of prophage-like ortholog groups in L. crispatus is substantially higher than the $9 \%$ reported for L. paracasei [38], indicating a large variation of prophagerelated gene contents among different Lactobacillus species. Interestingly, the prophage-like clusters were enriched in the nine vaginal isolates of $L$. crispatus, whereas there was none in the chicken isolate ST1 (Table 1, Figure 1), possibly reflecting exposure to phage in the human vagina. Specifically, the strains $125-2-\mathrm{CHN}$, SJ-3C-US, 214-1, JV-V01, FB077-07, and FB049-03 each contained between one and three prophage-like regions composed mostly of CDSs with phage-related or noninformative annotations and with no or limited homology with the genome sequence of other $L$. crispatus strains. The remaining three vaginal isolates (MV-3A-US, CTV-05, and MV-1A-US) carried six candidate prophages, each consisting mostly of orphan CDSs with phage-like or non-informative annotations. Sequence analysis of $L$. crispatus ST1 genome also revealed a prophage-like region, but this region was rejected, because associated with the strain's own replication machinery. Overall, the results are in accordance with the high degree of lysogeny, namely $77 \%$, observed for vaginal L. crispatus strains [85]. This suggests that temperate phages are widespread in vaginal lactobacilli and that transduction is an important mechanism for genome evolution in these bacteria. Notably, the lack of common insertion sites between the isolates indicates that various sites of the L. crispatus genomes can serve as targets for phage integration (Figure 1).

\section{CRISPR/Cas-systems}

CRISPRs are a family of DNA repeats present in the genomes of many prokaryotes that are responsible for providing acquired immunity to exogenous DNA from bacteriophages and plasmids. This system consists of a set of cas genes and an array of direct repeats separated by intervening sequence spacers derived from the invading DNA [64,88-90]. Interestingly, distinct types of CRISPR/ Cas systems were identified for the vaginal L. crispatus isolates and the chicken isolated ST1 (Table 2). All the vaginal isolates but the strain $125-2-\mathrm{CHN}$ were predicted to have several genes that could be classified to belong to the previously described Type II CRISPR/Cas system [64]. Analysis of the genome of $125-2-\mathrm{CHN}$ also revealed traces

Table 2 Distribution of Cas-proteins in L. crispatus

\begin{tabular}{|c|c|c|c|c|c|c|c|c|c|c|c|c|c|}
\hline $\begin{array}{l}\text { OrthoMCL- } \\
\text { family }\end{array}$ & Cas-model & $\begin{array}{l}125-2- \\
\text { CHN }\end{array}$ & $\begin{array}{c}214- \\
1\end{array}$ & $\begin{array}{l}\text { CTV- } \\
05\end{array}$ & $\begin{array}{l}\text { FB049- } \\
03\end{array}$ & $\begin{array}{c}\text { FB077- } \\
07\end{array}$ & $\begin{array}{l}\text { JV- } \\
\text { V01 }\end{array}$ & $\begin{array}{l}\text { MV-1A- } \\
\text { US }\end{array}$ & $\begin{array}{l}\text { MV-3A- } \\
\text { US }\end{array}$ & $\begin{array}{l}\text { SJ-3C- } \\
\text { US }\end{array}$ & ST1 & Total & $\begin{array}{c}\text { Total with } \\
\text { models }\end{array}$ \\
\hline LACT01579 & Csn2 & $1 / 1$ & $1 / 1$ & $1 / 1$ & $1 / 1$ & $1 / 1$ & $1 / 1$ & $1 / 1$ & $1 / 1$ & $1 / 1$ & 0 & 9 & 9 \\
\hline LACT01697 & Cas2 & 0 & $1 / 0$ & $1 / 1$ & $1 / 1$ & $1 / 1$ & $1 / 1$ & $1 / 1$ & $1 / 1$ & $1 / 0$ & 0 & 8 & 6 \\
\hline LACT01698 & Cas 1 & 0 & $1 / 1$ & $1 / 1$ & $1 / 1$ & $1 / 1$ & $1 / 1$ & $1 / 1$ & $1 / 1$ & $1 / 1$ & 0 & 7 & 7 \\
\hline LACT01822 & Csn2 & 0 & $1 / 1$ & $1 / 1$ & $1 / 1$ & $1 / 1$ & $1 / 1$ & 0 & $1 / 1$ & $1 / 1$ & 0 & 7 & 7 \\
\hline LACT01823 & Cas9/Csn1 & 0 & $1 / 1$ & 0 & $1 / 0$ & $1 / 0$ & $1 / 1$ & $1 / 1$ & $1 / 1$ & $1 / 0$ & 0 & 7 & 4 \\
\hline LACT01825 & Cas9/Csn1 & 0 & 0 & $1 / 0$ & $1 / 1$ & $1 / 1$ & $1 / 0$ & $1 / 0$ & $1 / 0$ & $1 / 1$ & 0 & 7 & 3 \\
\hline LACT02396 & Cas9/Csn1 & 0 & 0 & 0 & $1 / 1$ & $1 / 1$ & 0 & 0 & 0 & $1 / 1$ & 0 & 3 & 3 \\
\hline LCRIS_01207 & cas-CT1978 & 0 & 0 & 0 & 0 & 0 & 0 & 0 & 0 & 0 & $1 / 1$ & 1 & 1 \\
\hline LCRIS_01209 & casE-Cse3 & 0 & 0 & 0 & 0 & 0 & 0 & 0 & 0 & 0 & $1 / 1$ & 1 & 1 \\
\hline LCRIS_01210 & $\begin{array}{l}\text { casD-Cas5e, } \\
\text { CRISPR-cas5 }\end{array}$ & 0 & 0 & 0 & 0 & 0 & 0 & 0 & 0 & 0 & $1 / 1$ & 1 & 1 \\
\hline LCRIS_01211 & casC-Cse4 & 0 & 0 & 0 & 0 & 0 & 0 & 0 & 0 & 0 & $1 / 1$ & 1 & 1 \\
\hline LCRIS_01212 & casB-cse2 & 0 & 0 & 0 & 0 & 0 & 0 & 0 & 0 & 0 & $1 / 1$ & 1 & 1 \\
\hline \multirow[t]{2}{*}{ LCRIS_01214 } & $\begin{array}{l}\text { Cas3-core, } \\
\text { Cas3-HD }\end{array}$ & 0 & 0 & 0 & 0 & 0 & 0 & 0 & 0 & 0 & $1 / 1$ & 1 & 1 \\
\hline & Total & $1 / 1$ & $5 / 4$ & $5 / 4$ & $7 / 6$ & $7 / 6$ & $6 / 5$ & $5 / 4$ & $6 / 5$ & $7 / 5$ & $6 / 6$ & 54 & 45 \\
\hline
\end{tabular}

The first number in the table cells describes the number of CDSs part of the Cas-protein associated ortholog group in a specific strain and the second number indicates the number of group members matching the Cas-model. 
of the Type II system, but the presence of universal cas1 and cas 2 core genes and the cas $9 / \operatorname{csn} 1$ signature genes could not be verified, because the region next to $\operatorname{csn} 2$ is disrupted by a sequencing gap. Nevertheless, the CRISPR arrays in each of the vaginal strains was composed of direct repeats with an identical consensus sequence of $36 \mathrm{bp}$ and two to six spacer sequences each. Homology searches between the identified spacers and public virus and plasmid sequences did not reveal the putative targets of these systems, which is in line with the previous spacer annotation survey [90] identifying a plasmid or virus target only for $30 \%$ of the spacer sequences in lactic acid bacteria. The lack of identified targets of the L. crispatus spacers points to a pool of not yet sequenced vaginal phages and plasmids. Interestingly, many spacers were identical across several of the vaginal strains (Figure 3), suggesting that these strains may share a recent ancestor or have encountered similar invading genetic elements in their past. It should be noted that these genome sequences are incomplete and that some spacers and repeats may have remained undetected. In addition, a Type I CRISPR/Cas system [64] was identified in the ST1 genome comprising eight cas genes and three CRISPR-arrays composed of direct repeats of $28 \mathrm{bp}$, and 14, 15, and 5 spacers. The repeats were highly similar and resembled a repeat discovered in 31 vaginal samples by Rho et al. [91]. However, the shortest array was positioned within a 423 bp long putative LCRIS_01228 gene and thus is most likely a false prediction. Similarly to the vaginal isolates, the spacers of these systems did not match any known plasmid or virus sequence.

Prompted by the observed differences between the prevalence of CRISPR/Cas systems in the vaginal strains and the chicken isolate, the distribution of the cas genes in 135 publicly available Lactobacillus genomes was tested (Additional file 7). Markedly, the Type II CRISPR/Cas system hits were more frequent in vaginal (18 of the 40 strains) than in non-vaginal lactobacilli (28 of the 95 strains; Fisher's exact test $p$-value 0.12 ), which suggests that the Type II system could be important in the vaginal environment. The prevalence of the other types of CRISPR/cas systems was not significantly different at alpha level 0.20.

\section{Metabolic pathway reconstruction}

Using the automatic annotation server KAAS [59], we were able to assign EC numbers to the members of 1,320 ortholog groups. Surprisingly, the majority of the enzymes belonged to the core groups (Additional file 8), which is somewhat different from the large intra-specific variation present within the metabolic contents of $O$. oeni [80] or L. paracasei [38]. In accordance with the high number of core genome-encoded enzymes, the in silico reconstruction of $L$. crispatus metabolic pathways suggests that the strains have a potential to utilize a

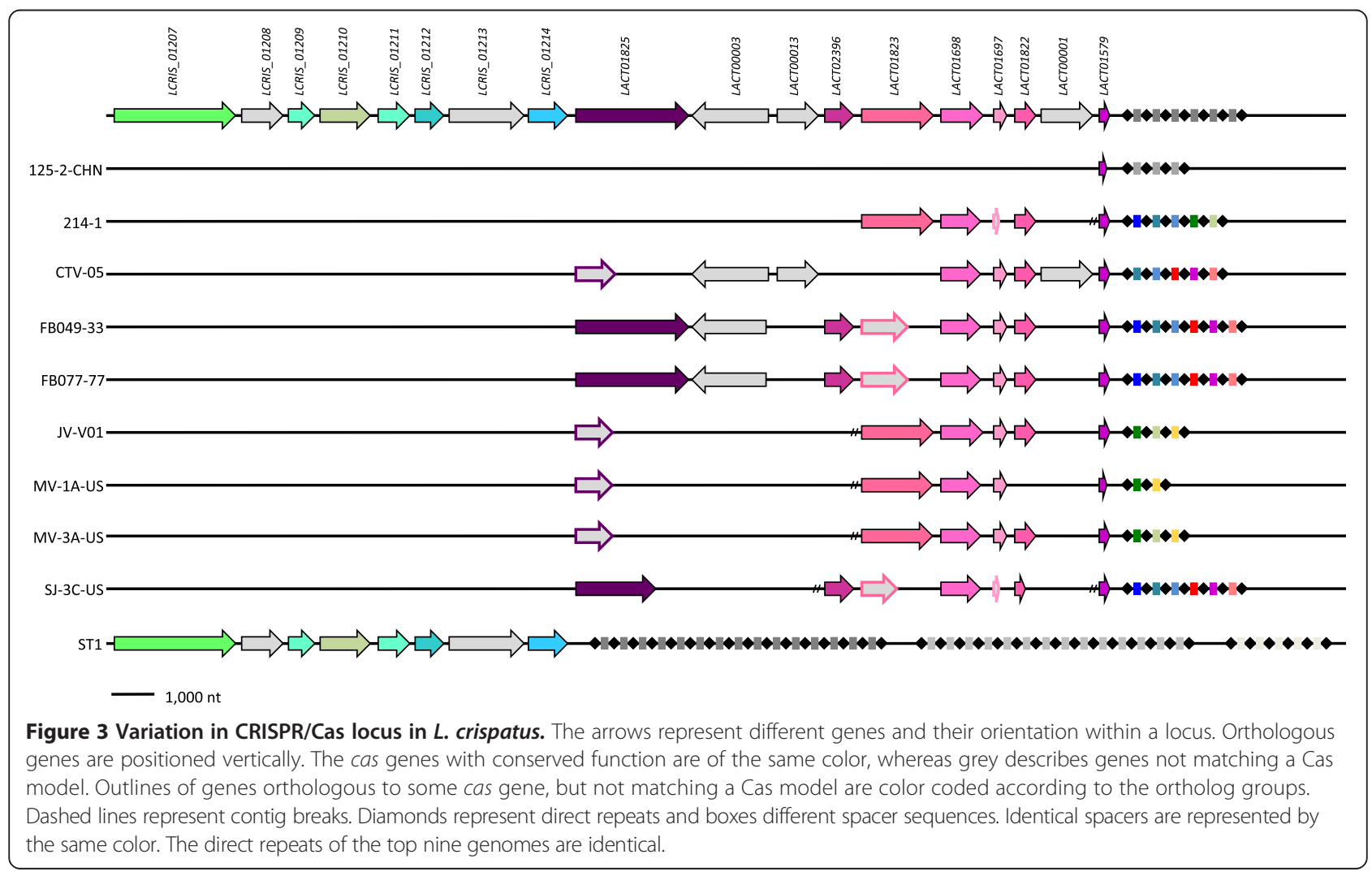


rather same set of carbohydrates (Additional file 9). The data supports the presence of metabolic routes in each strain for the conversion of a variety of sugars into the key intermediates of the pentose phosphate (D-Xylulose 5-phosphate), Embden-Meyerhof-Parnas (D-Fructose 1,6-bisphosphate), and tagatose-6-phosphate (tagatose-6phosphate) pathways. Pathways for the conversion of the D-Xylulose 5-phosphate and D-Fructose 1,6-bisphosphate into several of their end products were also annotated for nine of the ten strains. The aforementioned indicates the presence of both Embden-MeyerhofParnas and pentose phosphate pathways in the nine strains, which is typical for a heterofermentative species and contradictory to the previous classification of L. crispatus as a homofermentative species $[28,92]$. The exception is the strain CTV-05 that had only partial pathways for many end product conversions, most likely because of sequencing gaps in the corresponding genomic loci. No routes were recorded for the conversion of tagatose6-phosphate pathway intermediate into pyruvate in any of the strains. Interestingly, the data also shows evidence for the presence of strain-specific glycerone conversions in L. crispatus 125-2-CHN.

Regarding urogenital lifestyle, conserved pathways were annotated for the metabolism glucose and mannose, the former reported to be the major free monosaccharide and the latter a minor constituent of the vaginal fluid [93]. Although we did not detect complete routes for the metabolism of glycogen, seven vaginal strains were discovered to carry a gene coding for a type I pullulanase debranching enzyme (LACT01812), which could contribute to the degradation of glycogen. Moreover, L. crispatus core appears to encode a sialic acid utilization regulator (RpiR family) and an O-sialoglycoprotein endopeptidase that could contribute to the hydrolysis of $\mathrm{O}$-sialoglycoproteins in the vaginal mucosa. Notably, the manual examination of the enzyme contents revealed that each strain may generate hydrogen peroxide from pyruvate, of which the former acts as an antimicrobial compound.

We also assessed the range of amino acids that $L$. crispatus has a potential to synthetize (Additional file 9). Based on the in silico analyses of the biosynthetic capabilities, all strains can synthesize seven amino acids either de novo or as derivatives using the same pathways, which is three and four amino acids more than $L$ helveticus DPC 4571 [94] or L. acidophilus NCFM [84], respectively. Pathways for aspartate biosynthesis were also annotated in nine isolates, excluding the strain CTV-05 that did not share this property. We again speculate that the lack of biosynthesis route for aspartate is rather due to the draft nature of the genome sequence of this strain than a genuine loss. The other differences in amino-acid synthesis related to nuances in synthesis routes for cysteine, serine, and glycine, which seem to vary between isolates. Overall, the in silico analyses predicted a dependency on external supplies of amino acids for $L$. crispatus similar to that described for closely related lactobacilli $[84,95]$ and shows that the strains are rather similar in their biosynthetic power. Moreover, none of the detected conversions was deduced to be strain-specific, further highlighting the similarity.

\section{Proteinaceous adhesins}

Adhesion to host tissue has long been considered an important factor and a prerequisite for the long-term colonization of the human vagina, stimulation of the immune system, and antagonistic activity against harmful pathogens through competitive exclusion [96]. We screened the L. crispatus proteomes for adhesion and host colonization related domains and identified 103 proteins governing the ability of L. crispatus to colonize and interact with the host. These putative adhesins were associated with seven distinct types of adhesion-associated domains belonging to 21 ortholog groups of which seven are part of the L. crispatus core genome (Table 3, Additional file 10). It should be noted, however, that members of the same ortholog group did not necessarily share adhesion domains. In addition, six strain-specific adhesins were identified, all of which were predicted to be mucusbinding proteins. Interesting examples of the strainspecific adhesins include a sortase-anchored protein (LCRIS_00919) with multiple mucus-binding domains, and LCRIS_01654 being the only member of its ortholog group (LACT01522) with adhesion-associated domains. One notable core adhesin (LACT00800) was a putative fibronectin/fibrinogen-binding protein Fbpa, which has recently been proposed to contribute to the fibronectinbinding properties of Lactobacillus iners and to explain the stronger adhesion of $L$. iners to human fibronectin compared to other species of Lactobacillus tested in the study [97]. Notably, our data does not support this hypothesis, since the presence of functional $f b p a$ gene in the L. crispatus core genome should have resulted in equal adhesion abilities for the L. crispatus and L. iners strains tested in the study. Markedly, the recently characterized LEA protein of L. crispatus ST1 [33] belonging to LACT00252 was not identified, indicating that this adhesin binds to crop epithelium and epithelial cells from human vagina with some novel domain. In addition to the aforementioned putative adhesins, L. crispatus was predicted to harbor $\sim 30$ putative S-layer proteinencoding genes that could potentially contribute to bacterial adhesion. However, these predicted S-layer proteins were different from the S-layer proteins of other related lactobacilli reportedly implicated in bacterial adhesion $[42,98,99]$. 
Table 3 Distribution of adhesion related proteins in L. crispatus

\begin{tabular}{|c|c|c|c|c|c|c|c|c|c|c|c|c|c|}
\hline OrthoMCL- family & $\begin{array}{c}\text { Adhesion or } \\
\text { colonization } \\
\text { domain }\end{array}$ & $\begin{array}{l}\text { 125-2- } \\
\text { CHN }\end{array}$ & 214-1 & $\begin{array}{c}\text { CTV- } \\
05\end{array}$ & $\begin{array}{c}\text { FB049- } \\
03\end{array}$ & $\begin{array}{c}\text { FB077- } \\
07\end{array}$ & $\begin{array}{l}\text { JV- } \\
\text { V01 }\end{array}$ & $\begin{array}{c}\text { MV-1A- } \\
\text { US }\end{array}$ & $\begin{array}{c}\text { MV-3A- } \\
\text { US }\end{array}$ & $\begin{array}{l}\text { SJ-3C- } \\
\text { US }\end{array}$ & ST1 & Total & $\begin{array}{c}\text { Total with } \\
\text { domain }\end{array}$ \\
\hline LACT01267 & MucBP & $1 / 1$ & $1 / 0$ & $1 / 1$ & $1 / 1$ & $1 / 1$ & $1 / 0$ & 0 & $1 / 1$ & $1 / 1$ & $1 / 1$ & 9 & 7 \\
\hline LACT01522 & MucBP & $1 / 0$ & $1 / 0$ & 0 & $1 / 0$ & $1 / 0$ & $1 / 0$ & $1 / 0$ & $1 / 0$ & $1 / 0$ & $1 / 1$ & 9 & 1 \\
\hline LACT01644 & MucBP & 0 & $1 / 1$ & $1 / 1$ & $1 / 0$ & $1 / 0$ & $1 / 1$ & $1 / 0$ & $1 / 1$ & 0 & $1 / 1$ & 8 & 5 \\
\hline LACT01663 & MucBP & $1 / 1$ & $1 / 1$ & 0 & $1 / 1$ & $1 / 1$ & $1 / 1$ & $1 / 1$ & $1 / 1$ & $1 / 1$ & 0 & 8 & 8 \\
\hline LACT01712 & MucBP & $2 / 0$ & 0 & 0 & $1 / 1$ & $1 / 1$ & $1 / 0$ & $1 / 0$ & $1 / 0$ & $1 / 1$ & 0 & 7 & 3 \\
\hline LACT01924 & MucBP & $1 / 0$ & $1 / 1$ & 0 & $1 / 1$ & $1 / 1$ & $1 / 0$ & $1 / 0$ & 0 & 0 & 0 & 6 & 3 \\
\hline LACT02281 & MucBP & 0 & 0 & 0 & 0 & $1 / 1$ & $1 / 0$ & $1 / 1$ & 0 & 0 & 0 & 3 & 2 \\
\hline LACT02327 & MucBP & $1 / 0$ & 0 & 0 & 0 & 0 & $1 / 1$ & $1 / 0$ & 0 & 0 & 0 & 3 & 1 \\
\hline LACT02429 & MucBP & $2 / 2$ & 0 & 0 & 0 & 0 & 0 & 0 & 0 & 0 & 0 & 1 & 1 \\
\hline HMPREF9249_02429 & MucBP & 0 & 0 & 0 & 0 & $1 / 1$ & 0 & 0 & 0 & 0 & 0 & 1 & 1 \\
\hline HMPREF0506_0624 & MucBP & 0 & 0 & 0 & 0 & 0 & $1 / 1$ & 0 & 0 & 0 & 0 & 1 & 1 \\
\hline HMPREF0506_0871 & MucBP & 0 & 0 & 0 & 0 & 0 & $1 / 1$ & 0 & 0 & 0 & 0 & 1 & 1 \\
\hline LCRIS_00919 & MucBP & 0 & 0 & 0 & 0 & 0 & 0 & 0 & 0 & 0 & $1 / 1$ & 1 & 1 \\
\hline LACT00524 & Big_3 & $1 / 1$ & $1 / 1$ & $1 / 1$ & $1 / 1$ & $1 / 1$ & $1 / 1$ & $1 / 1$ & $1 / 1$ & $1 / 1$ & $1 / 1$ & 10 & 10 \\
\hline LACT00531 & Big_3 & $1 / 1$ & $1 / 1$ & $1 / 1$ & $1 / 1$ & $1 / 1$ & $1 / 1$ & $1 / 1$ & $1 / 1$ & $1 / 1$ & $1 / 1$ & 10 & 10 \\
\hline LACT00945 & Big_3 & $1 / 0$ & $1 / 0$ & $1 / 0$ & $1 / 1$ & $1 / 1$ & $1 / 1$ & $1 / 1$ & $1 / 1$ & $1 / 0$ & $1 / 1$ & 10 & 6 \\
\hline LACT02389 & Big_3 & 0 & $1 / 1$ & $1 / 1$ & 0 & 0 & 0 & 0 & 0 & $1 / 1$ & 0 & 3 & 3 \\
\hline LACT00169 & F5_F8_type_C & $1 / 1$ & $1 / 1$ & $1 / 1$ & $1 / 1$ & $1 / 1$ & $1 / 1$ & $1 / 1$ & $1 / 0$ & $1 / 1$ & $1 / 1$ & 10 & 9 \\
\hline LACT00800 & FbpA, DUF814 & $1 / 1$ & $1 / 1$ & $1 / 1$ & $1 / 1$ & $1 / 1$ & $1 / 1$ & $1 / 1$ & $1 / 1$ & $1 / 1$ & $1 / 1$ & 10 & 10 \\
\hline LACT00237 & FIVAR & $1 / 0$ & $1 / 1$ & $1 / 1$ & $1 / 1$ & $1 / 1$ & $1 / 1$ & $1 / 1$ & $1 / 1$ & $1 / 1$ & $1 / 1$ & 10 & 9 \\
\hline \multirow[t]{2}{*}{ LACT00212 } & fn3 & $1 / 1$ & $1 / 1$ & $1 / 1$ & $1 / 1$ & $1 / 1$ & $1 / 1$ & $1 / 1$ & $1 / 1$ & $1 / 1$ & $1 / 1$ & 10 & 10 \\
\hline & Total & $16 / 9$ & $13 / 10$ & $10 / 9$ & $13 / 11$ & $15 / 13$ & $17 / 12$ & $14 / 9$ & $12 / 9$ & $12 / 10$ & $11 / 11$ & 131 & 102 \\
\hline
\end{tabular}

The first number in the table cells describes the number of CDSs part of the ortholog group in a specific strain and the second the number indicates the number of group members having the adhesion or colonization related PFAM-domain(s).

\section{Cell wall exopolysaccharide}

In the L. crispatus genomes, a highly variable genome region appears to be associated with EPS biosynthesis. This EPS gene cluster was observed in eight $L$. crispatus strains and noted to comprise 37 EPS biosynthesis genes, five of which were present within each operon (Figure 4). The five conserved genes were predicted to encode a transcriptional regulator, a polymerization and chain length determination protein, a tyrosine-protein kinase, a protein-tyrosine phosphatase, and the priming glycosyltransferase. The remaining genes coded for proteins with putative glycosyl transferase functions, indicating that the strains produce EPSs with different sugar monomers and glycosidic linkages. Markedly, EPS gene clusters were not detected in the genomes of L. crispatus JV-V01 and 214-1.

\section{Antimicrobial potential in L. crispatus}

Lactobacillus species can maintain the vaginal ecosystem in a healthy condition by the production of antimicrobial substances such as lactic acid, hydrogen peroxide and bacteriocin-like substances $[9,96]$. Lactic acid is the main end product of the carbohydrate fermentation in lactobacilli and can contribute to the vaginal acidity and thereby inhibit the colonization and proliferation of harmful micro-organisms in the vagina [100]. The L. crispatus strains studied here appeared to possess between three to four L-lactate dehydrogenases for the conversion of puryvate into lactic acid. Interestingly, one specific $l d h$ locus found in five $L$. crispatus strains was flanked by a transposase enzyme gene that may affect its expression [101]. We also discovered hydrogen peroxide producing enzymes (EC:1.2.3.3 and EC:1.1.3.15) in each L. crispatus, which correlates well with the experimental data showing that hydrogen peroxide generation is common among vaginal L. crispatus [102].

Using BAGEL [63], the bacteriocin content of L. crispatus was investigated (Table 4). This method was able classify several sets of putative bacteriocin gene clusters in each strain, including at least two regions encoding bacteriolysins (similar to enterolysin A [103] and helveticin J [104]). In addition, regions implicated in the production of class II bacteriocins were revealed in the vaginal isolates. A pediocin-like bacteriocin that inhibits 


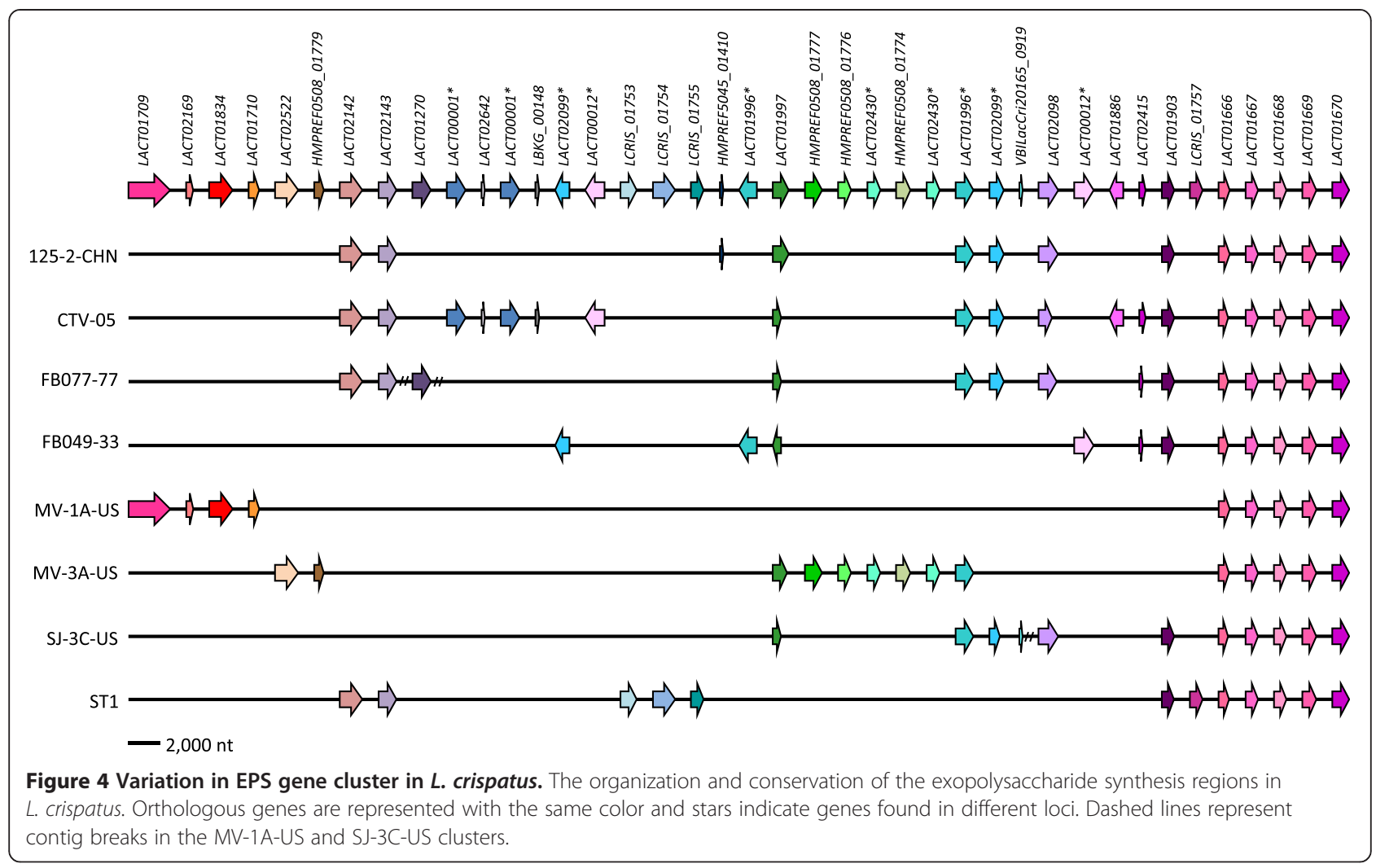

the growth of pathogenic Listeria and Clostridium species [105] was present in five vaginal isolates and all nine encoded a two-component bacteriocin LS2 that inhibits the growth of isolates belonging to genera Listeria, Shigella, and Yersinia [106]. Notably, the pediocin-like bacteriocin encoding genes were found in the vicinity of CDSs encoding proteins harboring a domain for Enterocin A immunity.

\section{Antagonistic activities against $G$. vaginalis}

$\mathrm{BV}$ is the most common vaginal disorders, affecting up to a third of women [107]. It has been associated with increased risk for preterm birth, urinary tract infections, and HIV infection, and represents a condition in which the normal protective lactobacilli community is replaced by an overgrowth of anaerobic bacteria [46]. Although the etiology of BV is not known, G. vaginalis is present in up to $95 \%$ of all BV cases [108], indicating that it could have a role in BV. In our efforts to decipher the genetic basis of the inhibitory actions of the species L. crispatus against G. vaginalis, we performed ortholog grouping of the available G. vaginalis data (Additional file 11) and used comparative genomics to identify shared

Table 4 Distribution of predicted bacteriocin related proteins in L. crispatus

\begin{tabular}{|c|c|c|c|c|c|c|c|c|c|c|c|c|c|c|}
\hline $\begin{array}{c}\text { Bacteriocin } \\
\text { class }\end{array}$ & $\begin{array}{l}\text { Bacteriocin } \\
\text { type }\end{array}$ & PFAM & $\begin{array}{l}125-2- \\
\text { CHN }\end{array}$ & 214-1 & $\begin{array}{l}\text { CTV- } \\
05\end{array}$ & $\begin{array}{c}\text { FB049- } \\
03\end{array}$ & $\begin{array}{c}\text { FB077- } \\
07\end{array}$ & $\begin{array}{l}\text { JV- } \\
\text { V01 }\end{array}$ & $\begin{array}{c}\text { MV- } \\
\text { 1A-US }\end{array}$ & $\begin{array}{c}\text { MV- } \\
\text { 3A-US }\end{array}$ & $\begin{array}{c}\text { SJ- } \\
3 \mathrm{C}-\mathrm{US}\end{array}$ & ST1 & Total & $\begin{array}{c}\text { Total with } \\
\text { domain }\end{array}$ \\
\hline \multirow{3}{*}{$\begin{array}{l}\text { Bacteriocins } \\
\text { larger than } \\
\text { 10kD, Class III }\end{array}$} & Enterolysin A & Peptidase_M23 & $1 / 1$ & $2 / 2$ & $2 / 2$ & $2 / 2$ & $2 / 2$ & $2 / 2$ & $2 / 2$ & $2 / 2$ & $2 / 2$ & $2 / 2$ & 10 & 10 \\
\hline & $\begin{array}{l}\text { Bacteriocin } \\
\text { helveticin J }\end{array}$ & - & 1 & 1 & 1 & 1 & 1 & 1 & 1 & 1 & 1 & 1 & 10 & - \\
\hline & Helveticin J & - & 1 & 1 & 1 & 1 & 2 & 1 & 1 & 1 & 1 & 1 & 10 & - \\
\hline LAPS & Small orfs & - & 1 & 0 & 0 & 1 & 1 & 0 & 1 & 0 & 0 & 0 & 4 & - \\
\hline \multirow{3}{*}{$\begin{array}{l}\text { Small unmodified } \\
\text { bacteriocins, } \\
\text { Class II }\end{array}$} & Penocin A & Bacteriocin_II & $1 / 2$ & 0 & $1 / 2$ & $1 / 2$ & $1 / 2$ & 0 & 0 & $1 / 2$ & $1 / 1$ & 0 & 6 & 6 \\
\hline & LS2, chain A & Bacteriocin_Ilc & $1 / 1$ & $1 / 1$ & $1 / 1$ & $1 / 1$ & $1 / 1$ & $1 / 1$ & $1 / 1$ & $1 / 1$ & $1 / 1$ & 0 & 9 & 9 \\
\hline & & Total & 7 & 5 & 7 & 8 & 9 & 5 & 6 & 7 & 6 & 4 & 49 & 25 \\
\hline
\end{tabular}

For the bacteriocin-like molecules with PFAM-domain, the first number in the table cells describes the number of CDSs part of the ortholog group in a specific strain, and the second number indicates the number of group members having the PFAM-domain. Helveticin J refers to the antimicrobial molecule first identified in L. helveticus and bacteriocin helveticin J to one identified in L. acidophilus. 
common molecular mechanisms between G. vaginalis and L. crispatus. Importantly, our analyses revealed several components by which L. crispatus could interfere with the attachment of $G$. vaginalis in the vagina. Firstly, fibronectin-binding could play a role in this process, given that proteins with FIVAR domains related to hyaluronate or fibronectin-binding were encoded in the core genomes of both G. vaginalis (GVAG00006) and L. crispatus (LACT00237). Secondly, searching L. crispatus proteins against the G. vaginalis HMM database suggested another L. crispatus protein (LACT01268), which could play a role in preventing the cell adhesion of G. vaginalis to fibronectin. Intriguingly, this counterpart of the G. vaginalis FIVAR-proteins was distributed in nine L. crispatus strains, but had no known adhesion domains. Another interesting core orholog group of G. vaginalis was GVAG00055. Many members of this ortholog group contained a bacterial Ig-like domain (PF12245), which is distantly related to the interaction domains, namely fn3 (PF00041) and Big_3 (PF07523), associated with several L. crispatus core adhesins (Table 3 ). Moreover, searches against the G. vaginalis HMMs revealed two additional $L$. crispatus adhesins (LACT01712 and LACT02327) that could act as counterparts of GVAG00055, although having mucin-binding domains (Table 3). Finally, of the three G. vaginalis pilusencoding gene clusters that were identified based on the pilus-encoding genes listed by Yeoman et al. [72], the one associated with most isolates had borderline (E-value $\leq 0.4$ ) counterparts in the L. crispatus core genome. Its major subunit pilin (GVAG00005) appears to have two potential antagonists in the L. crispatus core genome encoding a 12.8-kilodalton protein (LACT00214) and the LEA protein (LACT00252). In addition, the long CDS (GVAG00017) located next to the major subunit component in the cluster and showing similarity to known adhesins and surface antigens, could be inhibited by the members of the LACT01712 and LACT02440 based on the G. vaginalis HMM searches. Taken together, these findings indicate that $L$. crispatus could interfere with fibronectin-binding and pilus components of G. vaginalis.

Of the other listed virulence-related factors in G. vaginalis [72], the invasion-associated hydrolase (GVAG00614), protein with two G-related albuminbinding modules (GVAG01097), NLPA lipoprotein (GVAG00181), and endothelin-converting enzyme (GVAG00141) have potential antagonists encoded by the L. crispatus core based on the G. vaginalis HMM searches. A noteworthy finding is that the G-related albumin-binding module protein (GVAG01097) present in $17 \mathrm{G}$. vaginalis isolates shared similarity with 42 L. crispatus proteins, including all nine FIVAR-domain associated proteins of the LACT00237 (Table 3).

\section{Adhesion inhibition assays to HeLa cells}

Our comparative analysis described several species-wide factors by which $L$. crispatus could compete with $G$. vaginalis in the vagina. For example, the LEA protein was identified as a prominent counterpart of one of the G. vaginalis core adhesins and was thereby predicted to participate in the adherence inhibition of this pathogen. To validate the role of LEA in the antagonism against $G$. vaginalis, the adhesion capacity of a vaginal $L$. crispatus isolate EX533959VC06 and BV-associated G. vaginalis 101 to HeLa cells was tested using the previously described approach [17] with and without the pretreatment with Fab fragments prepared against LEA [33]. Markedly, the anti-LEA Fab fragments significantly reduced the adhesion level of both bacterial species to HeLa cells whereas the unrelated anti-flagellum Fab fragments showed no inhibitory effect (Figure 5). The reduction in adherence was most evident for the strain EX533959VC06; the anti-LEA Fab fragment pretreatment resulting in $90.6 \%(p$-value $\leq 0.033)$ and $89.8 \%(p$-value $\leq 0.024)$ reduction in adhesion to HeLa cells compared with the untreated or anti-flagellum Fab fragment pretreated bacteria, respectively. Intriguingly, pretreating G. vaginalis 101 with the anti-LEA Fab fragments caused also a significant reduction in adherence compared with the untreated bacterial cells $(65.6 \%$; $p$-value $\leq 0.005)$ or bacteria pretreated with the control anti-flagellum Fab fragments $(65.1 \% ; p$-value $\leq 0.019)$. These observations validated the predicted competitive character between LEA and G. vaginalis, suggesting a role for LEA in the previously identified ability of $L$. crispatus to exclude and displace G. vaginalis from HeLa cells [17]. The results also provide an explanation to the inverse association between L. crispatus and G. vaginalis colonization in the vagina $[12,44,47]$. Based on our comparative genomic analyses, the LEA protein achieves its inhibitory effect by competing with the same attachment sites as the pili of $G$. vaginalis. Of note, our adhesion assay provided a further support for the species-wide distribution of LEA among L. crispatus, since the strain EX533959VC06 has not yet been sequenced. Furthermore, since LEA has previously been studied only in the chicken isolate ST1 [33], our results serve as the first record of the functionality of LEA in vaginal L. crispatus.

\section{Phylogenetic relations}

Phylogentic relations between the selected L. crispatus strains and strains of closely related species $L$. acidophilus and $L$. helveticus were examined based on a maximumlikelihood tree built from the SNPs of the core genome. Altogether 38,726 conserved polymorphic sites were identified from the genome alignments and used for the construction of a phylogenetic tree. The phylogenetic tree (Figure 6) clearly shows that strains of the same 

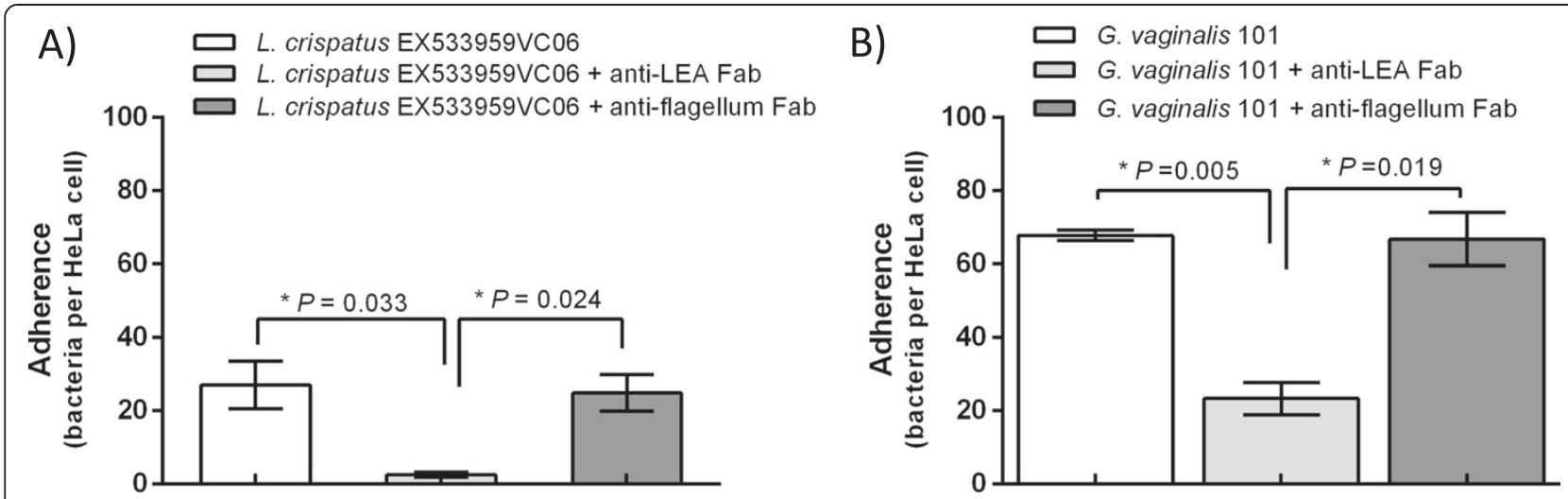

Figure 5 Inhibition of L. crispatus or G. vaginalis adhesion to HeLa cells by LEA-specific Fab fragments. Cells of L. crispatus EX533959VC06 (A) or G. vaginalis 101 (B) were pretreated with LEA-specific lgG Fab fragments or unrelated anti-flagellum Fab fragments or left untreated in PBS supplemented with $5 \mathrm{mM}$ PMSF before the adhesion assays. The number of adherent bacteria per epithelial cell in 20 randomly chosen microscopic fields was determined. The assay was performed twice with duplicate samples and the results show mean values of adherent bacteria. The asterisk indicates $P<0.05$ as calculated by Student's $t$ test.

species cluster together and that each Lactobacillus species has differentiated as a distinct entity. The species $L$. crispatus and L. helveticus share the most recent common ancestor and form a sister group to species $L$. acidophilus, which is accordance with previously reported phylogenetic trees $[29,109]$. Among the L. crispatus cluster, the chicken isolated ST1 branches off first from the vaginal isolates.

\section{Conclusions}

The rapidly increasing number of complete microbial genomes offers previously unimaginable possibilities to understand the phenotypic and genomic diversity in a particular species $[38,70,79,80]$. In this study, we have taken advantage of publicly available $L$. crispatus genomes and present the genetic landscape of this important urogenital lactic acid bacterium [7-12]. We assessed the overall genomic similarity of ten strains and defined the L. crispatus pan- and core genomes. These analyses depicted high sequence identity and extensive synteny punctuated by several GIs, and revealed a current pangenome that is nearly two times larger than the number of ortholog groups present in an average L. crispatus

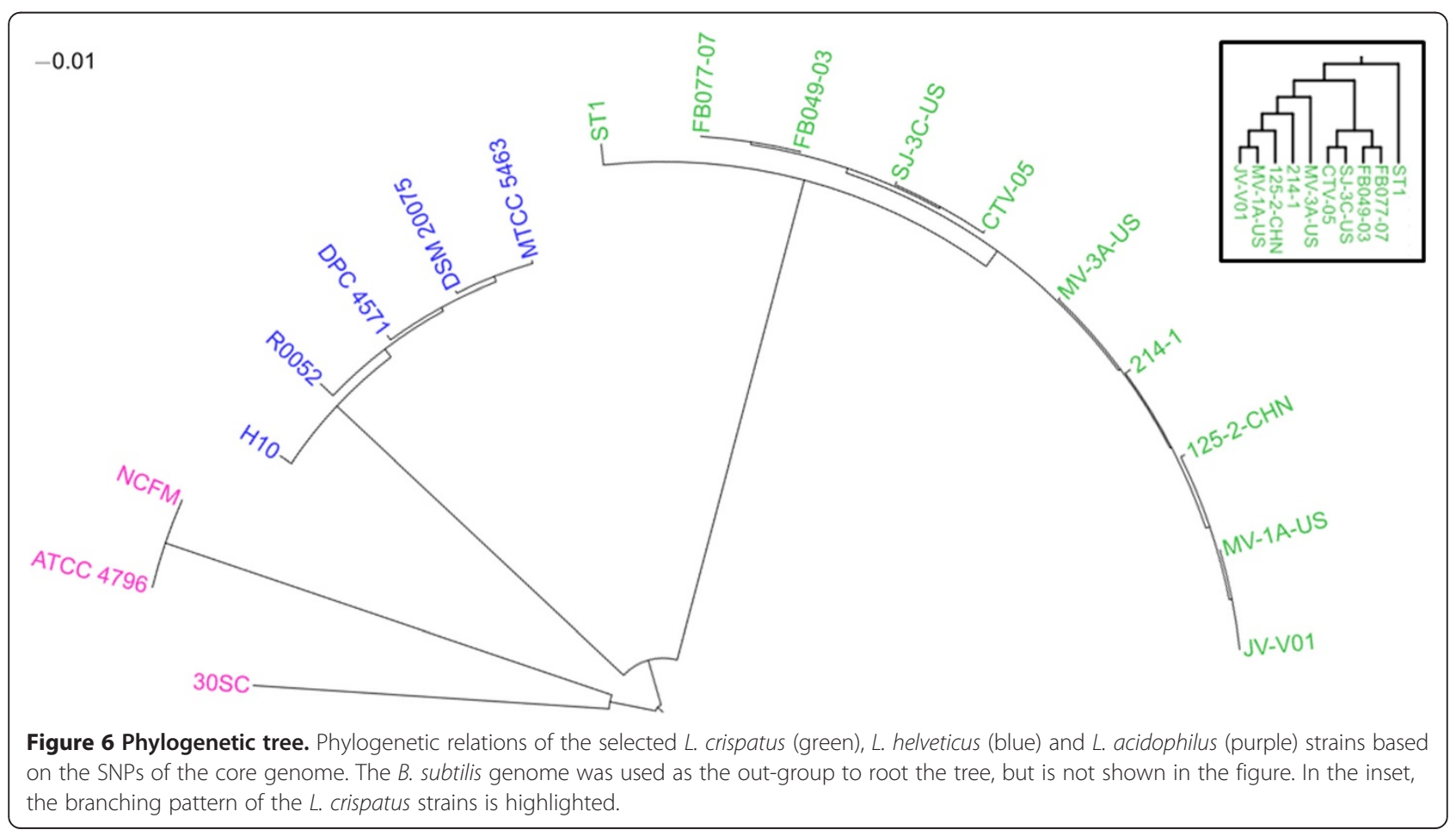


strain. About one third of all 3,929 ortholog groups were assigned to all strains, constituting the current L. crispatus core genome and encoding the basic aspects of $L$. crispatus biology. Importantly, these core features comprised several CDSs for the production of antimicrobial molecules and competitive exclusion of the BV associated species G. vaginalis, shedding light on the molecular mechanisms by which $L$. crispatus could maintain vaginal health. The pan-genome analysis also revealed 1,311 singleton ortholog groups associated with only one strain. The enrichment of functions related to replication and repair among these genes indicates the influence of transposons in genome evolution in this species. A third of the strain-specific ortholog groups had the highest similarity to genes found in the other strains of the L. delbrueckii clade, suggesting notable sequence influx from closely related lactobacilli. Our regression analysis indicates that the genetic diversity present within $L$. crispatus has not yet been comprehensively captured. Specifically, we estimate that over ten new ortholog groups will be discovered per every additional genome until almost $300 \mathrm{~L}$. crispatus strains have had their genomes defined. This estimation may be compromised by the uncertainty caused by the draft genomes that have up to 201 sequence gaps. Nevertheless, the data implies the presence of large repertoires of undiscovered L. crispatus genes to be sequenced in the future. The phylogenetic tree based on core genome SNPs among the ten isolates revealed that the chicken isolated ST1 branches off first from the L. crispatus cluster and that the L. acidophilus cluster is a sister taxon to L. helveticus and L. crispatus, as suggested earlier [29,109].

From the perspective of vaginal health, the most interesting genomic diversity regions in $L$. crispatus include the loci related to EPS biosynthesis, prophages and adaptive immunity, of which the latter two may play a role in BV. Firstly, the genetic differences in the composition of the EPS gene region may participate in the L. crispatus adhesion, biofilm formation and competitive exclusion of pathogens. The EPS-deficient strains JV-V01 and 214-1 are particularly interesting, as the deprivation of EPS has been reported to promote bacterial adhesion in other lactobacilli [110,111]. Secondly, the presence of prophage-like clusters in the vaginal $L$. crispatus genomes is in accordance with the previously observed [85] high level of lysogeny in vaginal L. crispatus strains. If truly inducible, the spontaneous release of the prophages could contribute to the development of BV [86]. Finally, a relationship was depicted between the life environment of the strains and their adaptive immunity systems, suggesting that different types CRISPR/Cas systems could be beneficial in different environments. This hypothesis is further supported by the analysis of the cas gene contents of 135 Lactobacillus genomes that revealed higher rates of the Type II CRISPR/Cas systems in vaginal than in non-vaginal lactobacilli. In addition, the CRISPR-arrays of the vaginal L. crispatus strains carry evidence of encounters with common invaders, as several of the spacer sequences were identical between several strains.

The defined $L$. crispatus core genome helps to explain how this species can thrive in the vaginal environment and benefit vaginal health. In the vaginal epithelium of reproductive age females, large quantities of glycogen are broken down and then metabolized into lactic acid, which is thought to result in acidification of the vagina $[112,113]$. Although L. crispatus lacks complete enzymatic machinery for glycogen degradation, the core genome encodes enzymatic pathways for the utilization of a range of carbohydrates available in the vaginal fluid, which could support the urogenital commensal lifestyle of L. crispatus. Encoded in the core are also several features potentially governing host-interactions and displaying an antagonistic activity against other microorganisms. Interestingly, the bacteriocin-like molecules encoded by the $L$. crispatus genomes could inhibit biofilm integrated G. vaginalis cells, shown to be more resistant to hydrogen peroxide and lactic acid than the cells in planktonic state [114]. Specifically, as G. vaginalis is known to develop an adherent biofilm on the vaginal epithelium in BV [115] this property could provide attractive means to restore the normal vaginal flora. In addition to the antimicrobial properties, L. crispatus was detected to contain several proteins that could mediate the previously reported [17] competitive exclusion of G. vaginalis from epithelial cells and explain the inverse association between $L$. crispatus and $G$. vaginalis colonization in the vagina $[12,44,47]$. Most notably, these specific interference mechanisms might include blocking the attachment of G. vaginalis by disturbing the pilus-mediated adhesion of the pathogen. This mechanism could involve LEA, shown here to be universally present in all L. crispatus strains, and demonstrated using LEA-specific Fab fragments to inhibit the adhesion of G. vaginalis adhesion to HeLa cells. Although LEA showed sequence similarity to a pilus component of G. vaginalis, further studies are still needed to decipher whether the counterpart of LEA is indeed the pilin subunit or some other adhesion associated molecule of $G$. vaginalis. In addition, we cannot rule out that surface molecules other than the ones recognized by the anti-LEA Fab fragments have participated in the contact between G. vaginalis and the host cell, since the Fab fragments did not abolish the adhesion completely. Nevertheless, the LEA protein appears to be a key mediator of the competitive exclusion of $G$. vaginalis.

In summary, we have presented a comparative analysis of ten $L$. crispatus genomes available within the public 
databases at the time of this study and provided a comprehensive look on the pan-genomic structure of this important urogenital species. Furthermore, our analyses revealed a list of core genes implicated in protecting the urogenital tract from G. vaginalis colonization, providing new insights into the treatment and prevention of BV.

\section{Additional files}

Additional file 1: Overview of $G$. vaginalis strains and properties. In the table, the genomic properties of the $G$. vaginalis strains used in this study are given. HMP refers to the Human Microbiome Project.

Additional file 2: List of $L$. helveticus, L. acidophilus and B. subtilis genomes included in the phylogenetic analysis. The accession is given for each genome.

Additional file 3: List of PFAM domains used in the annotation of putative $L$. crispatus adhesins. The accession, ID, and description are given for each PFAM matching an adhesion or colonization related keyword. Ones in the remaining columns indicate that the PFAM matched some L. crispatus CDS, passed the manual curation process and was included in the final list of adhesion or colonization related domains.

Additional file 4: The start and end compounds used in the metabolism screens. This table describes the compound pairs related to the de novo synthesis and interconversion of amino acids and carbohydrate metabolism.

Additional file 5: The $L$. crispatus data table. Results of the different bioinformatic analyses for each $L$. crispatus CDS.

Additional file 6: Reservoirs of genetic variability. This table describes the distribution of best BLAST hits of strain-specific L. crispatus CDSs.

Additional file 7: Prevalence of different types of CRISPR/Cas systems in vaginal and non-vaginal lactobacilli.

Additional file 8: Variation in metabolism related enzymes in L. crispatus. The horizontal lines represent the orthologous groups with assigned EC numbers and the different strains are indicated at the bottom of the picture. The presence of a given ortholog group in a specific strain is indicated with grey (single copy) or dark grey (duplicated genes). The absence of a given ortholog group is indicated with light grey. The colored bar on the left describes the conservation level of the ortholog groups and follows that of the Figure 2 (red indicates core genome and blue accessory genome with darkest shade indicating conservation in nine strains and lightest blue strain-specific). The dendrogram was generated using ward linkage clustering of the presence/absence data.

Additional file 9: Detected metabolic routes between different carbohydrate metabolism compounds and between different amino acid biosynthesis related compounds. The presence of intact metabolic route from one compound to another is indicated for each L. crispatus genome. Pathways found in the core genome analysis are marked with yellow color.

Additional file 10: Domain organization of $L$. crispatus adhesion and colonization factors. A representative member of each OrthoMCL-group is presented graphically. The larger colored blocks represent adhesion or colonization related PFAM-domains and the thinner blocks other domains. The names of each color-coded domain are given at the bottom of the picture.

Additional file 11: Overview of $G$. vaginalis ortholog groups. For each group, the associated proteins, PFAM domains, matching proteins in L. crispatus, the total number of matching proteins in L. crispatus, and total number of $L$. crispatus genomes providing the matches are given in the table.

\section{Abbreviations}

BV: Bacterial vaginosis; Cas: CRISPR-associated; CDS: Coding sequence CFUs: Colony forming units; COG: Cluster of orthologous groups; CRISPR: Clustered regularly interspaced short palindromic repeat; EPS: Exopolysaccharide; GI: Genomic Island; GIT: Gastrointestinal tract;
GUT: Genitourinary tract; HGT: Horizontal gene transfer; HMM: Hidden Markov model; LEA: Lactobacillus epithelium adhesin; OD: Optical density; PBS: Phosphate buffered saline; PFA: Paraformaldehyde; PMSF: Phenylmethylsulfonyl fluoride; RUTI: Recurrent urinary tract infection; SNP: Single nucleotide polymorphism.

\section{Competing interests}

The authors declare that they have no competing interests.

\section{Authors' contributions}

TO designed experiments and the adhesion experiments, analyzed the genomic data and prepared the manuscript. MK designed experiments, analyzed the genomic data and prepared the manuscript. JC performed the adhesion assays, analyzed the adhesion data and participated in preparing the manuscript. NC designed the adhesion experiments, analyzed the adhesion data and participated in preparing the manuscript. SE provided the Fab fragments. BWW designed the adhesion experiments and participated in preparing the manuscript. LP participated in preparing the manuscript. LH participated in preparing the manuscript. PA participated in preparing the manuscript. All authors read, commented and approved the final manuscript.

\section{Acknowledgements}

We thank Viikki Doctoral Programme in Molecular Biosciences (VGSB) and Integrative Life Science Doctoral Program (ILS) for supporting this study, Helmi Pett for useful suggestions for improving the manuscript, and Kimberly Jefferson for providing L. crispatus strain EX533959VC06.

\section{Author details}

'Institute of Biotechnology, University of Helsinki, Viikinkaari 4, PO Box 56, Fl-00014 Helsinki, Finland. 'Institute for Molecular Medicine Finland (FIMM), University of Helsinki, Tukholmankatu 8, PO Box 20, Fl-00014 Helsinki, Finland.

${ }^{3}$ Centre of Biological Engineering (CEB), Laboratory of Research in Biofilms Rosário Oliveira (LIBRO), University of Minho, Campus de Gualtar, 4710-057 Braga, Portugal. ${ }^{4}$ Functional Foods Forum, University of Turku, Turku Fl-20520, Finland. ${ }^{5}$ Department of Biosciences, Division of General Microbiology, University of Helsinki, Viikinkaari 9c, PO Box 56, Fl-00014 Helsinki, Finland. ${ }^{6}$ Department of Biosciences, Division of Genetics, University of Helsinki, Viikinkaari 5, PO Box 56, Fl-00014 Helsinki, Finland.

Received: 14 July 2014 Accepted: 24 November 2014

Published: 5 December 2014

\section{References}

1. Siezen RJ, Wilson G: Probiotics genomics. J Microbial Biotechnol 2010, 3(1):1-9.

2. Ventura M, O'Flaherty S, Claesson MJ, Turroni F, Klaenhammer TR, van Sinderen D, O'Toole PW: Genome-scale analyses of health-promoting bacteria: probiogenomics. Nat Rev Microbiol 2009, 7(1):61-71.

3. Uehara S, Monden K, Nomoto K, Seno Y, Kariyama R, Kumon H: A pilot study evaluating the safety and effectiveness of Lactobacillus vaginal suppositories in patients with recurrent urinary tract infection. Int $J$ Antimicrob Agents 2006, 28(Suppl 1):S30-4

4. Stapleton AE, Au-Yeung M, Hooton TM, Fredricks DN, Roberts PL, Czaja CA, Yarova-Yarovaya Y, Fiedler T, Cox M, Stamm WE: Randomized, placebo-controlled phase 2 trial of a Lactobacillus crispatus probiotic given intravaginally for prevention of recurrent urinary tract infection. Clin Infect Dis 2011, 52(10):1212-1217.

5. Hemmerling A, Harrison W, Schroeder A, Park J, Korn A, Shiboski S, Cohen CR Phase 1 dose-ranging safety trial of Lactobacillus crispatus CTV-05 for the prevention of bacterial vaginosis. Sex Transm Dis 2009, 36(9):564-569.

6. Antonio MA, Meyn LA, Murray PJ, Busse B, Hillier SL: Vaginal colonization by probiotic Lactobacillus crispatus CTV-05 is decreased by sexual activity and endogenous Lactobacilli. J Infect Dis 2009, 199(10):1506-1513.

7. Lamont RF, Sobel JD, Akins RA, Hassan SS, Chaiworapongsa T, Kusanovic JP, Romero $R$ : The vaginal microbiome: new information about genital tract flora using molecular based techniques. BJOG 2011, 118(5):533-549.

8. Ravel J, Gajer P, Abdo Z, Schneider GM, Koenig SS, McCulle SL, Karlebach S, Gorle R, Russell J, Tacket CO, Brotman RM, Davis CC, Ault K, Peralta L, Forney LJ: Vaginal microbiome of reproductive-age women. Proc Natl Acad SCi U S A 2011, 108(Suppl 1):4680-4687. 
9. Witkin SS, Linhares IM, Giraldo P: Bacterial flora of the female genital tract: function and immune regulation. Best Pract Res Clin Obstet Gynaecol 2007 21(3):347-354

10. Macklaim J, Fernandes A, Di Bella J, Hammond J, Reid G, Gloor G: Comparative meta-RNA-seq of the vaginal microbiota and differential expression by Lactobacillus iners in health and dysbiosis. Microbiome 2013, 1(1):12.

11. Verstraelen $H$, Verhelst $R$, Claeys $G$, De Backer $E$, Temmerman $M$, Vaneechoutte M: Longitudinal analysis of the vaginal microflora in pregnancy suggests that L. crispatus promotes the stability of the normal vaginal microflora and that $L$. gasseri and/or L. iners are more conducive to the occurrence of abnormal vaginal microflora. BMC Microbiol 2009, 9:116-2180-9-116.

12. Fredricks DN, Fiedler TL, Thomas KK, Oakley BB, Marrazzo JM: Targeted PCR for detection of vaginal bacteria associated with bacterial vaginosis. J Clin Microbiol 2007, 45(10):3270-3276.

13. Zárate $G$, Nader-Macias ME: Influence of probiotic vaginal lactobacilli on in vitro adhesion of urogenital pathogens to vaginal epithelial cells Lett Appl Microbiol 2006, 43(2):174-180.

14. Osset J, Bartolomé RM, García E, Andreu A: Assessment of the capacity of Lactobacillus to inhibit the growth of uropathogens and block their adhesion to vaginal epithelial cells. J Infect Dis 2001, 183(3):485-491.

15. Atassi F, Brassart D, Grob P, Graf F, Servin AL: Vaginal Lactobacillus isolates inhibit uropathogenic Escherichia coli. FEMS Microbiol Lett 2006, 257(1):132-138.

16. Teixeira GS, Carvalho FP, Arantes RM, Nunes AC, Moreira JL, Mendonca M, Almeida RB, Farias LM, Carvalho MA, Nicoli JR: Characteristics of Lactobacillus and Gardnerella vaginalis from women with or without bacterial vaginosis and their relationships in gnotobiotic mice. J Med Microbiol 2012, 61(Pt 8):1074-1081.

17. Castro J, Henriques A, Machado A, Henriques M, Jefferson KK, Cerca N: Reciprocal interference between Lactobacillus spp. and Gardnerella vaginalis on initial adherence to epithelial cells. Int J Med Sci 2013, 10(9):1193-1198.

18. Abbas Hilmi HT, Surakka A, Apajalahti J, Saris PE: Identification of the most abundant lactobacillus species in the crop of 1- and 5-week-old broiler chickens. Appl Environ Microbiol 2007, 73(24):7867-7873.

19. Yuki N, Shimazaki T, Kushiro A, Watanabe K, Uchida K, Yuyama T, Morotomi M: Colonization of the stratified squamous epithelium of the nonsecreting area of horse stomach by lactobacilli. Appl Environ Microbiol 2000, 66(11):5030-5034.

20. De Angelis M, Siragusa S, Berloco M, Caputo L, Settanni L, Alfonsi G, Amerio M, Grandi A, Ragni A, Gobbetti M: Selection of potential probiotic lactobacilli from pig feces to be used as additives in pelleted feeding. Res Microbiol 2006, 157(8):792-801.

21. Walter J, Hertel C, Tannock GW, Lis CM, Munro K, Hammes WP: Detection of Lactobacillus, Pediococcus, Leuconostoc, and Weissella species in human feces by using group-specific PCR primers and denaturing gradient gel electrophoresis. App/ Environ Microbiol 2001, 67(6):2578-2585.

22. Kleerebezem M, Vaughan EE: Probiotic and gut lactobacilli and bifidobacteria: molecular approaches to study diversity and activity. Annu Rev Microbiol 2009, 63:269-290.

23. Walter J: Ecological role of lactobacilli in the gastrointestinal tract: implications for fundamental and biomedical research. Appl Environ Microbiol 2008, 74(16):4985-4996.

24. Marrazzo JM, Fiedler TL, Srinivasan S, Thomas KK, Liu C, Ko D, Xie H, Saracino M, Fredricks DN: Extravaginal reservoirs of vaginal bacteria as risk factors for incident bacterial vaginosis. J Infect Dis 2012, 205(10):1580-1588.

25. Antonio MA, Rabe LK, Hillier SL: Colonization of the rectum by Lactobacillus species and decreased risk of bacterial vaginosis. J Infect Dis 2005, 192(3):394-398.

26. Nelson KE, Weinstock GM, Highlander SK, Worley KC, Creasy HH, Wortman JR, Rusch DB, Mitreva M, Sodergren E, Chinwalla AT, Feldgarden M, Gevers D, Haas BJ, Madupu R, Ward DV, Birren BW, Gibbs RA, Methe B, Petrosino JF, Strausberg RL, Sutton GG, White OR, Wilson RK, Durkin S, Giglio MG, Gujja S, Howarth C, Kodira CD, Kyrpides N, Mehta T, et al: A catalog of reference genomes from the human microbiome. Science 2010, 328(5981):994-999.

27. Ojala T, Kuparinen V, Koskinen JP, Alatalo E, Holm L, Auvinen P, Edelman S, Westerlund-Wikström B, Korhonen TK, Paulin L, Kankainen M: Genome sequence of Lactobacillus crispatus ST1. J Bacteriol 2010, 192(13):3547-3548
28. Salvetti E, Torriani S, Felis G: The Genus Lactobacillus: A Taxonomic Update. Probiotics Antimicrob Proteins 2012, 4(4):217-226.

29. Kant R, Blom J, Palva A, Siezen RJ, de Vos WM: Comparative genomics of Lactobacillus. Microb Biotechnol 2011, 4(3):323-332.

30. Edelman S, Leskelä S, Ron E, Apajalahti J, Korhonen TK: In vitro adhesion of an avian pathogenic Escherichia coli 078 strain to surfaces of the chicken intestinal tract and to ileal mucus. Vet Microbiol 2003, 91(1):41-56.

31. Edelman S: Mucosa-Adherent Lactobacilli: Commensal and Pathogenic Characteristics. University of Helsinki: Faculty of Biosciences, Department of Biological and Environmental Sciences, General Microbiology; 2005.

32. Edelman S, Westerlund-Wikström B, Leskelä S, Kettunen H, Rautonen N Apajalahti J, Korhonen TK: In vitro adhesion specificity of indigenous Lactobacilli within the avian intestinal tract. Appl Environ Microbiol 2002, 68(10):5155-5159.

33. Edelman SM, Lehti TA, Kainulainen V, Antikainen J, Kylväjä R, Baumann M, Westerlund-Wikström B, Korhonen TK: Identification of a high-molecular-mass Lactobacillus epithelium adhesin (LEA) of Lactobacillus crispatus ST1 that binds to stratified squamous epithelium. Microbiology 2012, 158(Pt 7):1713-1722.

34. Kaleta P, O'Callaghan J, Fitzgerald GF, Beresford TP, Ross RP: Crucial role for insertion sequence elements in Lactobacillus helveticus evolution as revealed by interstrain genomic comparison. Appl Environ Microbiol 2010, 76(1):212-220.

35. Berger B, Pridmore RD, Barretto C, Delmas-Julien F, Schreiber K, Arigoni F, Brussow $\mathrm{H}$ : Similarity and differences in the Lactobacillus acidophilus group identified by polyphasic analysis and comparative genomics. J Bacteriol 2007, 189(4):1311-1321.

36. Hao P, Zheng H, Yu Y, Ding G, Gu W, Chen S, Yu Z, Ren S, Oda M, Konno T, Wang S, Li X, Ji ZS, Zhao G: Complete sequencing and pan-genomic analysis of Lactobacillus delbrueckii subsp. bulgaricus reveal its genetic basis for industrial yogurt production. PLoS One 2011, 6(1):e15964.

37. Cremonesi P, Chessa S, Castiglioni B: Genome sequence and analysis of Lactobacillus helveticus. Front Microbiol 2012, 3:435.

38. Smokvina T, Wels M, Polka J, Chervaux C, Brisse S, Boekhorst J, van Hylckama Vlieg JE, Siezen RJ: Lactobacillus paracasei comparative genomics: towards species pan-genome definition and exploitation of diversity. PLoS One 2013, 8(7):e68731.

39. Douillard FP, Ribbera A, Kant R, Pietila TE, Jarvinen HM, Messing M Randazzo CL, Paulin L, Laine P, Ritari J, Caggia C, Lahteinen T, Brouns SJ, Satokari R, von Ossowski I, Reunanen J, Palva A, de Vos WM: Comparative genomic and functional analysis of 100 Lactobacillus rhamnosus strains and their comparison with strain GG. PLoS Genet 2013, 9(8):e1003683.

40. Raftis EJ, Salvetti E, Torriani S, Felis GE, O'Toole PW: Genomic diversity of Lactobacillus salivarius. Appl Environ Microbiol 2011, 77(3):954-965.

41. Toba T, Virkola R, Westerlund B, Björkman Y, Sillanpää J, Vartio T, Kalkkinen N, Korhonen TK: A Collagen-Binding S-Layer Protein in Lactobacillus crispatus. Appl Environ Microbiol 1995, 61(7):2467-2471.

42. Sillanpää J, Martinez B, Antikainen J, Toba T, Kalkkinen N, Tankka S, Lounatmaa K, Keränen J, Hook M, Westerlund-Wikström B, Pouwels PH, Korhonen TK: Characterization of the collagen-binding S-layer protein CbsA of Lactobacillus crispatus. J Bacterio/ 2000, 182(22):6440-6450.

43. Antikainen J, Anton L, Sillanpää J, Korhonen TK: Domains in the S-layer protein CbsA of Lactobacillus crispatus involved in adherence to collagens, laminin and lipoteichoic acids and in self-assembly. Mol Microbio/ 2002, 46(2):381-394

44. Shipitsyna E, Roos A, Datcu R, Hallen A, Fredlund H, Jensen JS, Engstrand L, Unemo M: Composition of the vaginal microbiota in women of reproductive age-sensitive and specific molecular diagnosis of bacterial vaginosis is possible? PLoS One 2013, 8(4):e60670.

45. Fredricks DN, Fiedler TL, Marrazzo JM: Molecular identification of bacteria associated with bacterial vaginosis. N Engl J Med 2005, 353(18):1899-1911.

46. Muzny CA, Schwebke JR: Gardnerella vaginalis: Still a Prime Suspect in the Pathogenesis of Bacterial Vaginosis. Curr Infect Dis Rep 2013, 15(2):130-135.

47. Srinivasan S, Hoffman NG, Morgan MT, Matsen FA, Fiedler TL, Hall RW, Ross FJ, McCoy CO, Bumgarner R, Marrazzo JM, Fredricks DN: Bacterial communities in women with bacterial vaginosis: high resolution phylogenetic analyses reveal relationships of microbiota to clinical criteria. PLoS One 2012, 7(6):e37818.

48. Benson DA, Clark K, Karsch-Mizrachi I, Lipman DJ, Ostell J, Sayers EW: GenBank. Nucleic Acids Res 2013, 41(Database issue):D36-D42. 
49. Gillespie JJ, Wattam AR, Cammer SA, Gabbard JL, Shukla MP, Dalay O, Driscoll T, Hix D, Mane SP, Mao C, Nordberg EK, Scott M, Schulman JR, Snyder EE, Sullivan DE, Wang C, Warren A, Williams KP, Xue T, Yoo HS, Zhang C, Zhang Y, Will R, Kenyon RW, Sobral BW: PATRIC: the comprehensive bacterial bioinformatics resource with a focus on human pathogenic species. Infect Immun 2011, 79(11):4286-4298.

50. Patterson JL, Stull-Lane A, Girerd PH, Jefferson KK: Analysis of adherence, biofilm formation and cytotoxicity suggests a greater virulence potential of Gardnerella vaginalis relative to other bacterial-vaginosis-associated anaerobes. Microbiology 2010, 156(Pt 2):392-399.

51. Rissman Al, Mau B, Biehl BS, Darling AE, Glasner JD, Perna NT: Reordering contigs of draft genomes using the Mauve aligner. Bioinformatics 2009, 25(16):2071-2073

52. Altschul SF, Madden TL, Schaffer AA, Zhang J, Zhang Z, Miller W, Lipman DJ: Gapped BLAST and PSI-BLAST: a new generation of protein database search programs. Nucleic Acids Res 1997, 25(17):3389-3402.

53. Carver TJ, Rutherford KM, Berriman M, Rajandream MA, Barrell BG, Parkhill J: ACT: the Artemis Comparison Tool. Bioinformatics 2005, 21(16):3422-3423.

54. Zhou F, XU Y: cBar: a computer program to distinguish plasmid-derived from chromosome-derived sequence fragments in metagenomics data. Bioinformatics 2010, 26(16):2051-2052

55. Guindon S, Gascuel O: A simple, fast, and accurate algorithm to estimate large phylogenies by maximum likelihood. Syst Biol 2003, 52(5):696-704.

56. Letunic I, Bork P: Interactive Tree Of Life (iTOL): an online tool for phylogenetic tree display and annotation. Bioinformatics 2007, 23(1):127-128.

57. Kankainen M, Ojala T, Holm L: BLANNOTATOR: enhanced homology-based function prediction of bacterial proteins. BMC Bioinformatics 2012, 13:33-2105-13-33.

58. Aziz RK, Bartels D, Best AA, DeJongh M, Disz T, Edwards RA, Formsma K, Gerdes S, Glass EM, Kubal M, Meyer F, Olsen GJ, Olson R, Osterman AL, Overbeek RA, McNeil LK, Paarmann D, Paczian T, Parrello B, Pusch GD, Reich C, Stevens R, Vassieva O, Vonstein V, Wilke A, Zagnitko O: The RAST Server: rapid annotations using subsystems technology. BMC Genomics 2008, 9:75-2164-9-75.

59. Moriya Y, Itoh M, Okuda S, Yoshizawa AC, Kanehisa M: KAAS: an automatic genome annotation and pathway reconstruction server. Nucleic Acids Res 2007, 35(Web Server issue):W182-5.

60. Tatusov RL, Fedorova ND, Jackson JD, Jacobs AR, Kiryutin B, Koonin EV Krylov DM, Mazumder R, Mekhedov SL, Nikolskaya AN, Rao BS, Smirnov S, Sverdlov AV, Vasudevan S, Wolf YI, Yin JJ, Natale DA: The COG database: an updated version includes eukaryotes. BMC Bioinformatics 2003, 4:41.

61. Finn RD, Tate J, Mistry J, Coggill PC, Sammut SJ, Hotz HR, Ceric G, Forslund K, Eddy SR, Sonnhammer EL, Bateman A: The Pfam protein families database. Nucleic Acids Res 2008, 36(Database issue):D281-8.

62. Eddy SR: A new generation of homology search tools based on probabilistic inference. Genome Inform 2009, 23(1):205-211.

63. van Heel AJ, de Jong A, Montalban-Lopez M, Kok J, Kuipers OP: BAGEL3. Automated identification of genes encoding bacteriocins and (non-) bactericidal posttranslationally modified peptides. Nucleic Acids Res 2013, 41(Web Server issue):W448-53.

64. Makarova KS, Haft DH, Barrangou R, Brouns SJ, Charpentier E, Horvath P, Moineau S, Mojica FJ, Wolf YI, Yakunin AF, van der Oost J, Koonin EV: Evolution and classification of the CRISPR-Cas systems. Nat Rev Microbiol 2011, 9(6):467-477

65. Haft DH, Selengut J, Mongodin EF, Nelson KE: A guild of 45 CRISPR-associated (Cas) protein families and multiple CRISPR/Cas subtypes exist in prokaryotic genomes. PLoS Comput Biol 2005, 1(6):e60.

66. Langille MG, Brinkman FS: IslandViewer: an integrated interface for computational identification and visualization of genomic islands. Bioinformatics 2009, 25(5):664-665.

67. Lima-Mendez G, Van Helden J, Toussaint A, Leplae R: Prophinder: a computational tool for prophage prediction in prokaryotic genomes. Bioinformatics 2008, 24(6):863-865.

68. Edgar RC: PILER-CR: fast and accurate identification of CRISPR repeats. BMC Bioinformatics 2007, 8:18.

69. Li L, Stoeckert CJ Jr, Roos DS: OrthoMCL: identification of ortholog groups for eukaryotic genomes. Genome Res 2003, 13(9):2178-2189.

70. Tettelin H, Riley D, Cattuto C, Medini D: Comparative genomics: the bacterial pan-genome. Curr Opin Microbiol 2008, 11(5):472-477.

71. Ihaka R, Gentleman R: R: A language for data analysis and graphics. J Comput Graph Stat 1996, 5(3):299-314.
72. Yeoman CJ, Yildirim S, Thomas SM, Durkin AS, Torralba M, Sutton G, Buhay CJ, Ding Y, Dugan-Rocha SP, Muzny DM, Qin X, Gibbs RA, Leigh SR, Stumpf R, White BA, Highlander SK, Nelson KE, Wilson BA: Comparative genomics of Gardnerella vaginalis strains reveals substantial differences in metabolic and virulence potential. PLoS One 2010, 5(8):e12411

73. Edgar RC: MUSCLE: a multiple sequence alignment method with reduced time and space complexity. BMC Bioinformatics 2004, 5:113.

74. Chou CH, Chang WC, Chiu CM, Huang CC, Huang HD: FMM: a web server for metabolic pathway reconstruction and comparative analysis. Nucleic Acids Res 2009, 37(Web Server issue):W129-34.

75. Kanehisa M, Goto S, Kawashima S, Okuno Y, Hattori M: The KEGG resource for deciphering the genome. Nucleic Acids Res 2004, 32(Database issue): D277-80.

76. Karp PD, Riley M, Paley SM, Pellegrini-Toole A: The MetaCyc Database. Nucleic Acids Res 2002, 30(1):59-61.

77. Machado A, Almeida C, Salgueiro D, Henriques A, Vaneechoutte M, Haesebrouck F, Vieira MJ, Rodrigues L, Azevedo NF, Cerca N: Fluorescence in situ Hybridization method using Peptide Nucleic Acid probes for rapid detection of Lactobacillus and Gardnerella spp. BMC Microbio/ 2013, 13:82-2180-13-82.

78. Siezen RJ, van Hylckama Vlieg JE: Genomic diversity and versatility of Lactobacillus plantarum, a natural metabolic engineer. Microb Cell Fact 2011, 10(Suppl 1):S3-2859-10-S1-S3. Epub 2011 Aug 30.

79. Medini D, Donati C, Tettelin H, Masignani V, Rappuoli R: The microbial pan-genome. Curr Opin Genet Dev 2005, 15(6):589-594.

80. Borneman AR, McCarthy JM, Chambers PJ, Bartowsky EJ: Comparative analysis of the Oenococcus oeni pan genome reveals genetic diversity in industrially-relevant pathways. BMC Genomics 2012, 13:373-2164-13-373.

81. van Tonder AJ, Mistry S, Bray JE, Hill DM, Cody AJ, Farmer CL, Klugman KP, von Gottberg A, Bentley SD, Parkhill J, Jolley KA, Maiden MC, Brueggemann $A B$ : Defining the estimated core genome of bacterial populations using a Bayesian decision model. PLoS Comput Biol 2014, 10(8):e1003788.

82. Broadbent JR, Neeno-Eckwall EC, Stahl B, Tandee K, Cai H, Morovic W, Horvath P, Heidenreich J, Perna NT, Barrangou R, Steele JL: Analysis of the Lactobacillus casei supragenome and its influence in species evolution and lifestyle adaptation. BMC Genomics 2012, 13:533-2164-13-533.

83. Lawrence JG: Gene transfer, speciation, and the evolution of bacterial genomes. Curr Opin Microbiol 1999, 2(5):519-523.

84. Altermann E, Russell WM, Azcarate-Peril MA, Barrangou R, Buck BL, McAuliffe O, Souther N, Dobson A, Duong T, Callanan M, Lick S, Hamrick A, Cano R, Klaenhammer TR: Complete genome sequence of the probiotic lactic acid bacterium Lactobacillus acidophilus NCFM. Proc Natl Acad Sci U S A 2005, 102(11):3906-3912

85. Damelin LH, Paximadis M, Mavri-Damelin D, Birkhead M, Lewis DA, Tiemessen $C T$ : Identification of predominant culturable vaginal Lactobacillus species and associated bacteriophages from women with and without vaginal discharge syndrome in South Africa. J Med Microbiol 2011, 60(Pt 2):180-183.

86. Kiliç AO, Pavlova SI, Alpay S, Kiliç SS, Tao L: Comparative study of vaginal Lactobacillus phages isolated from women in the United States and Turkey: prevalence, morphology, host range, and DNA homology. Clin Diagn Lab Immunol 2001, 8(1):31-39.

87. Pavlova SI, Kiliç AO, Mou SM, Tao L: Phage infection in vaginal lactobacilli: an in vitro study. Infect Dis Obstet Gynecol 1997, 5(1):36-44.

88. Barrangou R, Horvath P: CRISPR: new horizons in phage resistance and strain identification. Annu Rev Food Sci Technol 2012, 3:143-162.

89. Deveau H, Garneau JE, Moineau S: CRISPR/Cas system and its role in phage-bacteria interactions. Annu Rev Microbiol 2010, 64:475-493.

90. Horvath P, Coute-Monvoisin AC, Romero DA, Boyaval P, Fremaux C, Barrangou R: Comparative analysis of CRISPR loci in lactic acid bacteria genomes. Int J Food Microbiol 2009, 131(1):62-70.

91. Rho M, Wu YW, Tang H, Doak TG, Ye Y: Diverse CRISPRs evolving in human microbiomes. PLoS Genet 2012, 8(6):e1002441.

92. Hammes WP, Vogel RF: The genus Lactobacillus. In The genera of lactic acid bacteria. Edited by Wood BJB, Holzapfel WH. Glasgow: Blackie Academic \& Professional; 1995:19-54.

93. Rajan N, Cao Q, Anderson BE, Pruden DL, Sensibar J, Duncan JL, Schaeffer AJ: Roles of Glycoproteins and Oligosaccharides Found in Human Vaginal Fluid in Bacterial Adherence. Infect Immun 1999, 67(10):5027-5032.

94. Callanan M, Kaleta P, O'Callaghan J, O'Sullivan O, Jordan K, McAuliffe O, Sangrador-Vegas A, Slattery L, Fitzgerald GF, Beresford T, Ross RP: Genome 
sequence of Lactobacillus helveticus, an organism distinguished by selective gene loss and insertion sequence element expansion. J Bacteriol 2008, 190(2):727-735.

95. Pridmore RD, Berger B, Desiere F, Vilanova D, Barretto C, Pittet AC, Zwahlen MC, Rouvet M, Altermann E, Barrangou R, Mollet B, Mercenier A, Klaenhammer T, Arigoni F, Schell MA: The genome sequence of the probiotic intestinal bacterium Lactobacillus johnsonii NCC 533. Proc Natl Acad Sci U S A 2004, 101(8):2512-2517.

96. Boris $S$, Barbés $C$ : Role played by lactobacilli in controlling the population of vaginal pathogens. Microbes Infect 2000, 2(5):543-546.

97. McMillan A, Macklaim JM, Burton JP, Reid G: Adhesion of Lactobacillus iners $A B-1$ to Human fibronectin: a key mediator for persistence in the vagina? Reprod Sci 2013, 20(7):791-796.

98. Sun Z, Kong J, Hu S, Kong W, Lu W, Liu W: Characterization of a S-layer protein from Lactobacillus crispatus $\mathrm{K} 313$ and the domains responsible for binding to cell wall and adherence to collagen. Appl Microbiol Biotechnol 2013, 97(5):1941-1952.

99. Hynönen U, Westerlund-Wikström B, Palva A, Korhonen TK: Identification by flagellum display of an epithelial cell- and fibronectin-binding function in the SIpA surface protein of Lactobacillus brevis. J Bacteriol 2002, 184(12):3360-3367.

100. O'Hanlon DE, Moench TR, Cone RA: In vaginal fluid, bacteria associated with bacterial vaginosis can be suppressed with lactic acid but not hydrogen peroxide. BMC Infect Dis 2011, 11:200-2334-11-200.

101. Poirel L, Decousser JW, Nordmann P: Insertion sequence ISEcp1B is involved in expression and mobilization of a bla(CTX-M) beta-lactamase gene. Antimicrob Agents Chemother 2003, 47(9):2938-2945.

102. Antonio MA, Hawes SE, Hillier SL: The identification of vaginal Lactobacillus species and the demographic and microbiologic characteristics of women colonized by these species. J Infect Dis 1999, 180(6):1950-1956.

103. Nilsen T, Nes IF, Holo H: Enterolysin A, a cell wall-degrading bacteriocin from Enterococcus faecalis LMG 2333. Appl Environ Microbiol 2003, 69(5):2975-2984.

104. Joerger MC, Klaenhammer TR: Cloning, expression, and nucleotide sequence of the Lactobacillus helveticus 481 gene encoding the bacteriocin helveticin J. J Bacterio/ 1990, 172(11):6339-6347.

105. Diep DB, Godager L, Brede D, Nes IF: Data mining and characterization of a novel pediocin-like bacteriocin system from the genome of Pediococcus pentosaceus ATCC 25745. Microbiology 2006, 152(Pt 6):1649-1659.

106. Busarcevic M, Dalgalarrondo M: Purification and genetic characterisation of the novel bacteriocin LS2 produced by the human oral strain Lactobacillus salivarius BGHO1. Int J Antimicrob Agents 2012, 40(2):127-134.

107. Koumans EH, Sternberg M, Bruce C, McQuillan G, Kendrick J, Sutton M, Markowitz LE: The prevalence of bacterial vaginosis in the United States, 2001-2004; associations with symptoms, sexual behaviors, and reproductive health. Sex Transm Dis 2007, 34(11):864-869.

108. Marrazzo JM, Thomas KK, Fiedler TL, Ringwood K, Fredricks DN: Relationship of specific vaginal bacteria and bacterial vaginosis treatment failure in women who have sex with women. Ann Intern Med 2008, 149(1):20-28.

109. Chavagnat F, Haueter M, Jimeno J, Casey MG: Comparison of partial tuf gene sequences for the identification of lactobacilli. FEMS Microbiol Lett 2002, 217(2):177-183.

110. Lebeer S, Verhoeven TL, Francius G, Schoofs G, Lambrichts I, Dufrene Y, Vanderleyden J, De Keersmaecker SC: Identification of a Gene Cluster for the Biosynthesis of a Long, Galactose-Rich Exopolysaccharide in Lactobacillus rhamnosus GG and Functional Analysis of the Priming Glycosyltransferase. Appl Environ Microbiol 2009, 75(11):3554-3563.

111. Denou E, Pridmore RD, Berger B, Panoff JM, Arigoni F, Brussow H: Identification of genes associated with the long-gut-persistence phenotype of the probiotic Lactobacillus johnsonii strain NCC533 using a combination of genomics and transcriptome analysis. J Bacteriol 2008, 190(9):3161-3168.

112. Boskey ER, Telsch KM, Whaley KJ, Moench TR, Cone RA: Acid production by vaginal flora in vitro is consistent with the rate and extent of vaginal acidification. Infect Immun 1999, 67(10):5170-5175.

113. Boskey ER, Cone RA, Whaley KJ, Moench TR: Origins of vaginal acidity: high $\mathrm{D} / \mathrm{L}$ lactate ratio is consistent with bacteria being the primary source. Hum Reprod 2001, 16(9):1809-1813.
114. Patterson JL, Girerd PH, Karjane NW, Jefferson KK: Effect of biofilm phenotype on resistance of Gardnerella vaginalis to hydrogen peroxide and lactic acid. Am J Obstet Gynecol 2007, 197:170.e1-170.e7.

115. Swidsinski A, Mendling W, Loening-Baucke V, Ladhoff A, Swidsinski S, Hale LP, Lochs H: Adherent biofilms in bacterial vaginosis. Obstet Gynecol 2005, 106(5 Pt 1):1013-1023.

doi:10.1186/1471-2164-15-1070

Cite this article as: Ojala et al:: Comparative genomics of Lactobacillus crispatus suggests novel mechanisms for the competitive exclusion of Gardnerella vaginalis. BMC Genomics 2014 15:1070

\section{Submit your next manuscript to BioMed Central and take full advantage of:}

- Convenient online submission

- Thorough peer review

- No space constraints or color figure charges

- Immediate publication on acceptance

- Inclusion in PubMed, CAS, Scopus and Google Scholar

- Research which is freely available for redistribution

Submit your manuscript at www.biomedcentral.com/submit
C) BioMed Central 